\title{
Advances in Vehicular Ad-Hoc Networks (VANETs): Challenges and Road-map for Future Development
}

\author{
Elias C. Eze, Sijing Zhang, Enjie Liu, Joy C. Eze \\ Centre for Wireless Research, Institute for Research in Applicable Computing (IRAC), Department of Computer Science and \\ Technology, University of Bedfordshire, Luton, LU1 3JU, England \\ \{elias.eze, joy.eze1\}@study.beds.ac.uk, \{sijing.zhang, enjie.liu\}@beds.ac.uk
}

\begin{abstract}
Recent advances in wireless communication technologies and auto-mobile industry have triggered a significant research interest in the field of VANETs over the past few years. Vehicular Network consists of vehicle-to-vehicle (V2V) and vehicle-to-infrastructure (V2I) communications supported by wireless access technologies such as IEEE 802.11p. This innovation in wireless communication has been envisaged to improve road safety and motor traffic efficiency in near future through the development of Intelligent Transport Systems (ITS). Hence, government, auto-mobile industries and academia are heavily partnering through several ongoing research projects to establish standards for VANETs. The typical set of VANET application areas, such as vehicle collision warning and traffic information dissemination have made VANET an interesting field of mobile wireless communication. This paper provides an overview on current research state, challenges, potentials of VANETs as well the ways forward to achieving the long awaited ITS.
\end{abstract}

Keywords: Vehicular communication, V2V, V2I, ITS, IEEE 802.11p, WAVE, IEEE 1609.

\section{Introduction}

Road accidents has been on an alarming increase despite the introduction of several innovative in-vehicle safety-oriented devices such as anti-locking braking system (ABS), seatbelts, airbags, rear-view cameras, electronic stability control (ESC). Several studies have maintained that $60 \%$ of the accidents that occur on motorways could be avoided if warning messages were provided to the drivers just few seconds prior to moment of crash [1] [2].

The possibility of direct exchange of kinematic data between vehicles over an ad-hoc network environment called a vehicular ad-hoc network (VANET) has been widely perceived by governments, car manufacturing industries and academia as a promising concept for future realization of intelligent transportation system (ITS) thereby achieving safety and efficiency in our nearly overcrowded motorways. The VANET is a sub-class of MANET where the mobile nodes are vehicles. When compared with Mobile Ad-Hoc Network (MANET) and other cellular systems, inter-vehicle communication (IVC) has four major advantages: broad coverage area, relatively low latency due to direct wireless communication, little or no power issue as well as no service fees.

In the recent years, car manufacturing industries, academia and government agencies have started putting much joint efforts together towards realizing the concept of vehicular communications in wide scale. Some frameworks are already worked out with the first landmark of standardization processes made by US Federal Communications Communication (FCC) through the allocation of $75 \mathrm{MHz}$ of dedicated short range communication (DSRC) spectrum [3] basically to accommodate $\mathrm{V} 2 \mathrm{~V}$ and V2I communications for safety-related applications. Table I shows the DSRC standards designated for use in USA, Japan and Europe [4-5].
Potentials envisaged in VANETs have led to numerous vehicular communications research with their associated standardization projects in many countries across the world. These projects include DSRC development by Vehicle Safety Communications Consortium (VSCC) [6] (USA), European automotive industry project co-funded by the European Communication Commission (ECC) to foster road safety through the development and demonstration of preventive safety-related applications/technologies called PReVENT project [7-8] (Europe), Internet ITS Consortium [9] and Advanced Safety Vehicle project [10] (Japan), Car-2-Car Communications Consortium (C2C-CC) [11], Vehicle Infrastructure Integration program (VII) [12], Secure Vehicle Communication (SeVeCOM) [13], and Network on Wheels project [14] (Germany). In September 2003, both IEEE and American Society for Testing and Materials (ASTM) Committee E2213-03 ${ }^{[15]}$ adopted an amendment of the legacy IEEE wireless LAN standard done by an IEEE Task Group (TG). The amendment is denoted by IEEE $802.11 \mathrm{p}$ as the platform for Wireless Access in Vehicular Environment (WAVE) which will be used to enable wireless communications between moving vehicles within a coverage distance of $1000 \mathrm{~m}$ in a free space (i.e. highway scenario) and $300 \mathrm{~m}$ in non-free space (i.e. urban scenario). Fig. 1 shows the ASTM endorsed DSRC standard structure for DSRC link and data link layer.

The rest of this paper is organized as follows. Section II presents a brief overview of VANET. Application of VANET is presented in Section III while the current VANET open research challenges and certain ideas on possible solutions are presented in Section IV. Final conclusion of this paper is presented in Section V.

\section{Overview of VANETs}

In VANETs, participating vehicles are equipped with set of wireless sensors and On Board Units (OBUs) to allow for possibility of wireless communication between the vehicles and their environs. These devices make each vehicle function as packet sender, receiver and router which enable 


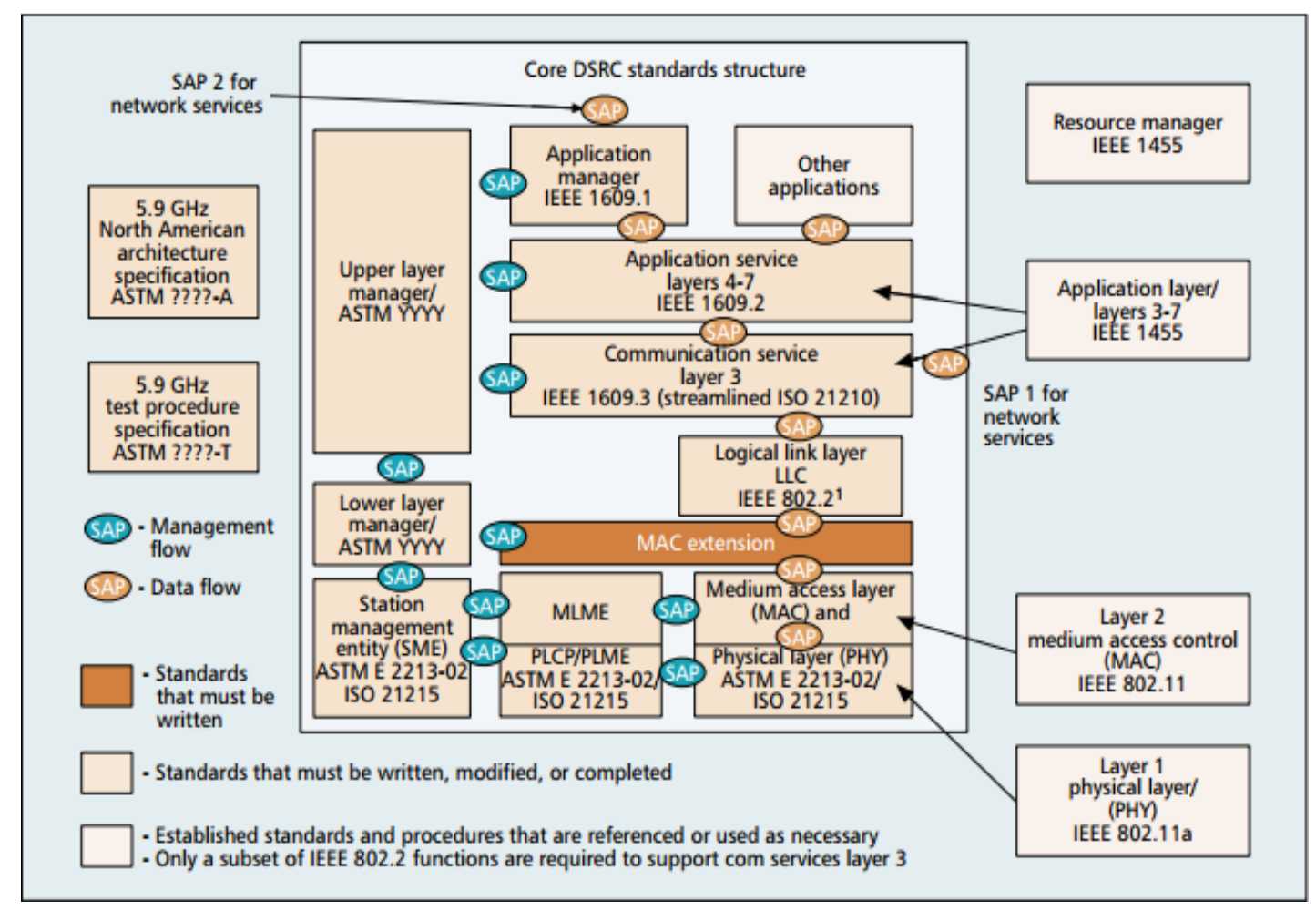

Fig. 1 ASTM endorsed DSRC standards structure.

TABLE I. DSRC STANDARDS USED IN THE USA, JAPAN AND EUROPE

\begin{tabular}{|l|l|l|l|}
\hline Features & USA ASTM & $\begin{array}{l}\text { Japan (Association of radio } \\
\text { Industries and business) }\end{array}$ & $\begin{array}{l}\text { Europe (European } \\
\text { committee for } \\
\text { standardization) }\end{array}$ \\
\hline Communication & half-duplex & $\begin{array}{l}\text { half-duplex (OBU) } \\
\text { full duplex (RSU) }\end{array}$ & half-duplex \\
\hline Band & $75 \mathrm{MHz}$ & $80 \mathrm{MHz}$ & $20 \mathrm{MHz}$ \\
\hline Channels & 7 & $\begin{array}{l}\text { downlink: } 7 \\
\text { uplink: } 7\end{array}$ & 4 \\
\hline Transmission range & $1000 \mathrm{~m}$ & $30 \mathrm{~m}$ & $15-20 \mathrm{~m}$ \\
\hline Data rate & $\begin{array}{l}1-27 \mathrm{MBps} \\
(\text { downlink/uplink) }\end{array}$ & $\begin{array}{l}1 / 4 \mathrm{MBps} \\
\text { (downlink/uplink) }\end{array}$ & $\begin{array}{l}\text { downlink: } 500 \mathrm{KBps} \\
\text { uplink: } 250 \mathrm{KBps}\end{array}$ \\
\hline Radio frequency & $5.9 \mathrm{GHz}$ & $5.8 \mathrm{GHz}$ & $5.8 \mathrm{GHz}$ \\
\hline Channel separation & $10 \mathrm{MHz}$ & $5 \mathrm{MHz}$ & $5 \mathrm{MHz}$ \\
\hline
\end{tabular}

the vehicles send and receive messages to other vehicles or road side units (RSUs) within their reach via wireless medium. These sets of wireless sensors, OBUs or some typical radio interfaces enable vehicles form short-range wireless ad-hoc networks to broadcast kinematic data to vehicular networks or transportation authorities/agencies which process and use the data to foster traffic efficiency and safety on the motorways [16]. VANET-enabled vehicles are fitted with the appropriate hardware which allows for acquisition and processing of location (or position) data such as those from global positioning system (GPS) or differential global positioning system (DGPS) receiver [17]. The fixed RSUs are connected to the backbone network and situated at strategic positions across the roads to aid effective, reliable and timely vehicular communications. RSUs are equipped with network devices to support dedicated short-range wireless communication using IEEE $802.11 \mathrm{p}$ radio technology. The possible vehicular communication configurations in intelligent transportation system (ITS) include vehicle-to-vehicle (or inter-vehicle), vehicle-to-infrastructure and routing-based (RB) communication (see Fig. 2).

Vehicles can directly establish communication wirelessly with one another forming $\mathrm{V} 2 \mathrm{~V}$ communication or with fixed RSUs forming V2I communications. These vehicular communication configurations rely heavily on acquisition of accurate and up-to-date kinematic data of both the vehicles and the surrounding environment with the aid of positioning systems and intelligent wireless communication protocols and access technologies for reliable, efficient and timely information exchange. Considering the network environment of VANETs with unreliable, shared communication medium and limited bandwidth [18], smart 
cross-layer communication protocols are required to guarantee reliable and efficient delivery of data packets to all vehicles and infrastructures (RSUs) within the vehicles' radio signal transmission coverage.

\section{VANET Application}

The concept of equipping future vehicles with sets of wireless sensors, on-board units, Global Positioning System (GPS) or Differential Global Positioning System (DGPS) receivers and network interfaces presents an ample opportunity to achieve intelligent transportation systems with wireless- enabled vehicles capable of sending and receiving kinematic data on the road. VANET is the bedrock upon which vehicles will be able to gather, process and distribute information both for safety-related and non-safety-related purposes on our motorways. Extensive areas of potential VANET applications have been listed and evaluated by several researchers through different projects and consortia. Typically, these applications are classified into either safety-related or non-safety-related applications.

\subsection{Safety-related VANET applications}

Safety-related VANET applications are classified into three basic categories, namely: driver assistance (co-operative collision avoidance, road navigation and lane changing), alert information (work zone and speed limit alert information) and warning alert (road obstacle, post-crash and other life-threatening traffic condition warning).The vehicular safety communications consortium has listed eight (8) potential safety-related applications [19]: pre-crash sensing, curve speed, lane-change, traffic signal violation, emergency electronic brake light and co-operative forward collision alert, stop sign movement and left turn assistant. Safety-related messages from these applications normally require direct communication owing to their stringent delay requirement. For instance, in the case of a sudden hard breaking or accident, the vehicles following those ones involved in accident as well as those in opposite direction will be sent a notification message.

Major road safety applications are the primary measures taken to reduce (or eliminate) the probability of traffic accidents and loss of life in our motorways [10] [20-21]. Some of the traffic accidents that occur annually across the world are as a result of intersection, rear-end, head-on and lateral mobile vehicle collisions. The necessary precautionary measures (or traffic warning systems) required for the effective implementation and deployment of this road safety applications with their required use-case, mode of communication, minimum transmission frequency and acceptable latency are summarized in Table II. These active road safety-related applications offer assistance to drivers through the provision of time-sensitive, life-saving traffic information which enables drivers to avoid collisions with other mobile vehicles on the road. This is achieved through the timely and reliable exchange of safety-related kinematic information amongst vehicles through $\mathrm{V} 2 \mathrm{~V}$ communication system as well as amongst vehicles and other road infrastructures through V2I communication, which is processed to predict traffic accidents and collisions. This kinematic information contains the vehicle's current location, intersection position, speed, acceleration and direction of movement, to create the awareness of the presence of other vehicles on the road. Moreover, most of

TABLE II. DESCRIPTION OF SELECTED USE-CASES AND CORRESPONDING TECHNICAL REQUIREMENTS OF ROAD SAFETY-RELATED APPLICATIONS

\begin{tabular}{|c|c|c|c|}
\hline Use-case & $\begin{array}{l}\text { Mode of } \\
\text { communication }\end{array}$ & $\begin{array}{l}\text { Minimum } \\
\text { transmission } \\
\text { frequency }\end{array}$ & $\begin{array}{l}\text { Required } \\
\text { latency }\end{array}$ \\
\hline $\begin{array}{l}\text { Intersection } \\
\text { collision } \\
\text { warning. }\end{array}$ & $\begin{array}{l}\text { Periodic message } \\
\text { Broadcasting }\end{array}$ & $\begin{array}{l}\text { Minimum } \\
\text { frequency: } \\
10 \mathrm{~Hz}\end{array}$ & $\begin{array}{l}\text { Less than } \\
100 \mathrm{~ms}\end{array}$ \\
\hline $\begin{array}{l}\text { Lane change } \\
\text { Assistance }\end{array}$ & $\begin{array}{l}\text { Co-operation } \\
\text { awareness between } \\
\text { vehicles }\end{array}$ & $\begin{array}{l}\text { Minimum } \\
\text { frequency: } \\
10 \mathrm{~Hz}\end{array}$ & $\begin{array}{l}\text { Less than } \\
100 \mathrm{~ms}\end{array}$ \\
\hline $\begin{array}{l}\text { Overtaking } \\
\text { vehicle } \\
\text { warning }\end{array}$ & $\begin{array}{l}\text { Broadcast of } \\
\text { overtaking state }\end{array}$ & $\begin{array}{l}\text { Minimum } \\
\text { frequency: } \\
10 \mathrm{~Hz}\end{array}$ & $\begin{array}{l}\text { Less than } \\
100 \mathrm{~ms}\end{array}$ \\
\hline $\begin{array}{l}\text { Head on } \\
\text { collision } \\
\text { warning }\end{array}$ & $\begin{array}{l}\text { Broadcasting } \\
\text { Messages }\end{array}$ & $\begin{array}{l}\text { Minimum } \\
\text { frequency: } \\
10 \mathrm{~Hz}\end{array}$ & $\begin{array}{l}\text { Less than } \\
100 \mathrm{~ms}\end{array}$ \\
\hline $\begin{array}{l}\text { Co-operative } \\
\text { forward } \\
\text { collision } \\
\text { warning } \\
\end{array}$ & $\begin{array}{l}\text { Co-operation } \\
\text { awareness between } \\
\text { vehicles associated } \\
\text { to unicast }\end{array}$ & $\begin{array}{l}\text { Minimum } \\
\text { frequency: } \\
10 \mathrm{~Hz}\end{array}$ & $\begin{array}{l}\text { Less than } \\
100 \mathrm{~ms}\end{array}$ \\
\hline $\begin{array}{l}\text { Emergency } \\
\text { vehicle } \\
\text { warning }\end{array}$ & $\begin{array}{l}\text { Periodic } \\
\text { permanent } \\
\text { message } \\
\text { broadcasting }\end{array}$ & $\begin{array}{l}\text { Minimum } \\
\text { frequency: } \\
10 \mathrm{~Hz}\end{array}$ & $\begin{array}{l}\text { Less than } \\
100 \mathrm{~ms}\end{array}$ \\
\hline $\begin{array}{l}\text { Co-operative } \\
\text { merging } \\
\text { assistance }\end{array}$ & $\begin{array}{l}\text { Co-operation } \\
\text { awareness between } \\
\text { vehicles associated } \\
\text { to unicast }\end{array}$ & $\begin{array}{l}\text { Minimum } \\
\text { frequency: } \\
10 \mathrm{~Hz}\end{array}$ & $\begin{array}{l}\text { Less than } \\
100 \mathrm{~ms}\end{array}$ \\
\hline $\begin{array}{l}\text { Collision risk } \\
\text { warning }\end{array}$ & $\begin{array}{l}\text { Time limited } \\
\text { periodic messages } \\
\text { on event }\end{array}$ & $\begin{array}{l}\text { Minimum } \\
\text { frequency: } \\
10 \mathrm{~Hz}\end{array}$ & $\begin{array}{l}\text { Less than } \\
100 \mathrm{~ms}\end{array}$ \\
\hline
\end{tabular}

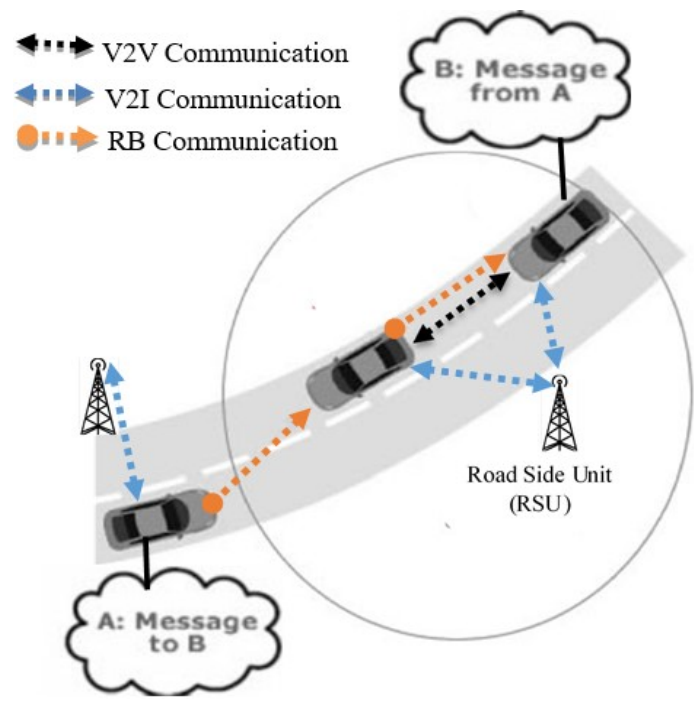

Fig. 2 Possible vehicular communication configurations in Intelligent Transport Systems (ITS)

these life-critical messages in vehicular communications are broadcast-oriented, time-sensitive, life-saving, safety-related messages which must have deep penetration across the 
entire network and must be reliably delivered to the intended recipients within a short time.

\subsection{Non-safety-related VANET applications}

The non-safety-related applications of VANETs are also referred to as comfort or commercial applications. Typically, these applications aim to improve traffic efficiency, passenger comfort and commercial platforms in terms of advertisements and electronic toll collection (ETC). These applications include provision of weather information, current traffic and the ability to locate various Points of Interest (PoI) such as nearest parking lots, gas stations, shopping malls, hotels, fast food restaurants, etc. The owners of these aforementioned businesses can install some stationary gateways to transmit marketing adverts for the mobile customers travelling via the VANET enabled vehicles. The compelling argument in allowing comfort and commercial VANET applications is that of distraction and interference with safety-related applications thereby defeating the aim of improving safety and traffic efficiency in our motorways. Consequently, a possible solution would be achieved by using separate physical network channels for safety and non-safety applications or by applying traffic prioritization where safety-related messages are accorded higher priority than non-safety-related messages.

\section{Open research challenges and possible solutions for vehicular networks}

The current key research challenge of VANETs is the lack of central communication co-coordinator associated with all the existing wireless access technologies earmarked for VANET set-up, implementation and deployment. Deploying wireless communication in vehicular environment effectively requires that some intrinsic issues ranging from technical application development and deployment up to economic concerns must be resolved. Though VANET is a form of MANET, its behaviour and characteristics are fundamentally different. Some of the basic VANET research challenges that must be addressed to achieve effective vehicular communication are briefly discussed below.

\subsection{Comparison of high-speed wireless communication technologies for vehicular networks}

Many high-speed wireless access technologies and standards have been suggested, recommended and considered for use in VANET connectivity by many researchers [17] [19] (see Table III). Some of the technologies and air interface protocols capable of supporting high-speed communication in vehicular environment which are currently being considered for VANETs include:

\subsubsection{Cellular technology - (2G, 2.5G...4G)}

The $2 \mathrm{G}$ and $2.5 \mathrm{G}$ technologies provide reliable security and wide communication coverage while $3 \mathrm{G}$ and $4 \mathrm{G}$ technologies which are swiftly taking over offer highly improved communication capacity and bandwidth. In USA, Europe and Japan, many fleet and telematics projects are already using different generations of cellular technology [17]. However, the apparent high cost coupled with its high latency rate and limited bandwidth discourages its possible use as future communication base for VANETs.

\subsubsection{IEEE 802.11p based standards}

ASTM and IEEE-adopted amendment is a variation of IEEE 802.11 family meant to support wireless communication in vehicular environment. This air interface protocol is a work-in-progress by IEEE Working Group that would provide inter-vehicle communication (IVC) and vehicle-to-roadside communication at vehicular speed ranging from 200 to $300 \mathrm{~km} / \mathrm{h}$ covering communication range of $1000 \mathrm{~m}$. The medium access control (MAC) and physical (PHY) layers are based on IEEE 802.11a. IEEE $802.11 \mathrm{p}$ technology is heavily promoted by vehicle manufacturing industries across the globe especially in USA through VII and VSCC, Japan through Advanced Safety Vehicle project (ASV), Europe through $\mathrm{C} 2 \mathrm{C}-\mathrm{CC}$ and

TABLE III: COMPARISON OF HIGH-SPEED WIRELESS COMMUNICATION TECHNOLOGIES FOR VEHICULAR NETWORKS

\begin{tabular}{|l|l|l|l|l|}
\hline \multirow{2}{*}{$\begin{array}{l}\text { Indicative wireless } \\
\text { features }\end{array}$} & \multicolumn{4}{|l|}{ Communication technologies } \\
\cline { 2 - 5 } & Wi-Fi & $\mathbf{8 0 2 . 1 1 p}$ (WAVE) & Infrared & Cellular \\
\hline Standards & IEEE & IEEE, ISO, ETSI & ISO & ETSI, 3GPP \\
\hline Channel bandwidth & $1-40 \mathrm{MHz}$ & $10 \mathrm{MHz}, 20 \mathrm{MHz}$ & N/A (optical carrier) & $\begin{array}{l}25 \mathrm{MHz}(\mathrm{GSM}), \\
60 \mathrm{MHz} \text { (UMTS) }\end{array}$ \\
\hline Allocated spectrum & $\begin{array}{l}50 \mathrm{MHz} @ 2.5 \mathrm{GHz} \\
300 \mathrm{MHz} @ 5 \mathrm{GHz}\end{array}$ & $\begin{array}{l}30 \mathrm{MHz}(\mathrm{EU}) \\
75 \mathrm{MHz} \text { (US) }\end{array}$ & N/A (optical carrier) & (Operator-dependent) \\
\hline Frequency band(s) & $2.4 \mathrm{GHz}, 5.2 \mathrm{GHz}$ & $5.86-5.92 \mathrm{GHz}$ & $835-1035 \mathrm{~nm}$ & $\begin{array}{l}800 \mathrm{MHz}, 900 \mathrm{MHz} \\
1800 \mathrm{MHz}, 1900 \mathrm{MHz}\end{array}$ \\
\hline Communication range & $<100 \mathrm{~m}$ & $<1000 \mathrm{~m}$ & $<100 \mathrm{~m}$ (CALM IR) & $<15 \mathrm{~km}$ \\
\hline Suitability for mobility & Low & High & Medium & High \\
\hline Bit rate & $6-54 \mathrm{Mb} / \mathrm{s}$ & $3-27 \mathrm{Mb} / \mathrm{s}$ & $\begin{array}{l}<1 \mathrm{Mb} / \mathrm{s} \\
<2 \mathrm{Mb} / \mathrm{s}\end{array}$ & $<2 \mathrm{Mb} / \mathrm{s}$ \\
\hline $\begin{array}{l}\text { Transmission power for } \\
\text { mobile node }\end{array}$ & $100 \mathrm{~mW}$ & $\begin{array}{l}2 \mathrm{~W} \mathrm{EIRP} \mathrm{(EU)} \\
760 \mathrm{~mW} \text { (US) }\end{array}$ & $\begin{array}{l}12800 \quad \mathrm{~W} / \mathrm{Sr} \text { pulse } \\
\text { peak }\end{array}$ & $\begin{array}{l}380 \mathrm{~mW} \text { (UMTS) } \\
2000 \mathrm{~mW} \text { (GSM) }\end{array}$ \\
\hline
\end{tabular}


Germany through SeVeCOM. Due to substantial production volumes, the estimated deployment cost of IEEE $802.11 \mathrm{p}$ is predicted to be relatively low when compared with cellular technology. Hence, this nascent technology also called WAVE has an edge over cellular technologies and fairly more suitable for VANETs.

\subsubsection{Unified wireless access}

The International Standards Organization- technical committee (ISO-TC 204 WG16) has performed the most significant unification efforts of the various existing wireless access technologies. The product of the unification process is a vehicular communication standard called the Continuous Air Interface for Long and Medium range (CALM M5) [19]. CALM M5 combined several related air interface protocols and parameters, building on top of IEEE $802.11 \mathrm{p}$ architecture with support for cellular technologies as discussed earlier. These standards combined into single, uniform standard are expected to provide improved vehicular network performance through increased capacity, flexibility and redundancy in packet transmission and reception.

\subsection{Spectrum allocation issues in VANETs}

The Federal Communication Commission (FCC) of US allocated a spectrum of $75 \mathrm{MHz}$ at $5.9 \mathrm{GHz}(5.850-$ $5.925 \mathrm{GHz}$ ) for vehicular communications (V2V and V2I). Most of the ongoing ITS Projects and Consortia (VII and VSC) have already adopted the derivative of IEEE 802.11 family of standards as the best suitable wireless access technology for communication systems using this spectrum [17]. Hence, the new amendment of 802.11 denoted as $802.11 \mathrm{p}$ and the unification of various existing wireless access technologies by ISO TC 204 WG16 (i.e. CALM M5 [19]) to allow moving vehicles utilize the officially allocated $75 \mathrm{MHz}$ at $5.9 \mathrm{GHz}$ band as discussed in Section 4.1 .3 above.

In Europe, the distributed short range communication (DSRC) band does not have a continuous spectrum of $75 \mathrm{MHz}$ as is the case in US. However, the C2C-CC of Europe has proposed an approach similar to US approach which allocates two $10 \mathrm{MHz}$ specifically for vehicular safety-related communications at $5.9 \mathrm{GHz} \quad(5.875-$ $5.925 \mathrm{GHz})$. The allocation of this band in Europe provided a sort of global harmonization given that the same band is used in US as control channel. Use of supplementary spectrum could be supported by this technology for non-safety-related (comfort and commercial) applications in several other bands such as
$5 \mathrm{GHz}$ RLAN or $5.8 \mathrm{GHz}$ IRM band [20].

At the moment, $5.9 \mathrm{GHz}$ band is allocated for stationary satellite services and military radar systems. Because a continuous spectrum of the US FCC officially allocated $75 \mathrm{MHz}$ in DSRC band is not available in Europe, the European Commission Car2Car $\mathrm{CC}$ has proposed a derivative of the FCC approach. The proposal allocates a $2 \times 10 \mathrm{MHz}$ for primary use of time-sensitive safety applications at $5.9 \mathrm{GHz}$ range $(5.875-5.925 \mathrm{GHz})$ and propose an additional spectrum at either in the $5 \mathrm{GHz}$ of RLAN band or in the $5.8 \mathrm{GHz}$ IRM band for non-safety (or infotainment) applications. However, the Short Range Device Maintenance Group (SRD/MG) of European Conference of Postal and Telecommunications Administrations (CEPT), and Electronic Communication Commission (ECC) has recommended to place the first proposed $10 \mathrm{MHz}$ control channel in $5.885-5.895 \mathrm{GHz}$ so as to align with the US FCC approach, and place the second proposed $10 \mathrm{MHz}$ channel in the upper part of the Industrial, Scientific and Medical (ISM) band (5.865 $5.875 \mathrm{GHz}$ ) to provide for radio-location services below $5.85 \mathrm{GHz}[19]$.

\subsection{Message broadcasting in VANET}

The envisaged VANET applications require transmission, gathering and processing of large volume of electronic messages/data packets. Message broadcasting has been seen as potential attractive alternative solution by automotive wireless networking researchers partly as a result of its low-cost and partly due to its support for vast potential volumes of data packets. Hence, several broadcasting techniques and mechanisms have been taken into consideration by many researchers. These techniques include restricted and unrestricted bandwidth digital service solutions as well as satellite broadcasting solution which has already incorporated real time traffic data services [22].

Broadcasting techniques are associated with broadcast storm problem [4]. This problem could be reduced or eliminated by reducing the message broadcast range specifically to the site of interest thereby reducing the unnecessary network overhead. This concept is called location-aware broadcasting. Another approach that has emerged as a promising solution is clustering approach where neighboring mobile vehicles form clusters, manageable groups which limit the message broadcasting range. Several cluster-based VANETs broadcasting protocols have been proposed as can be seen in the case of [23-25].

TABLE IV: A BRIEF COMPARISON OF SELECTED MESSAGE DISSEMINATION PROTOCOLS

\begin{tabular}{|l|l|l|l|l|l|}
\hline Protocol & $\begin{array}{l}\text { Retransmissions/ } \\
\text { Rebroadcasting }\end{array}$ & $\begin{array}{l}\text { Redundancy } \\
\text { Rate }\end{array}$ & Latency & $\begin{array}{l}\text { Delivery } \\
\text { Rate }\end{array}$ & $\begin{array}{l}\text { Memory } \\
\text { Requirement }\end{array}$ \\
\hline eMDR [26] & Yes & Low & Low & High & Not mentioned \\
\hline NSF/NJL [27] & Yes & Low & Low & High & Not mentioned \\
\hline RTAD [28] & Yes & Low & Low & High & Not mentioned \\
\hline TRADE [29] & No & High & Medium & Medium & Yes \\
\hline DDT [29] & No & High & Medium & Medium & Yes \\
\hline ODAM [30] & No & Medium & Low & Medium & Yes \\
\hline SBA [31] & Yes & Medium & Low & Medium & Yes \\
\hline CBD [32] & No & Medium & Low & Medium & Yes \\
\hline
\end{tabular}




\begin{tabular}{|l|l|l|l|l|l|}
\hline TRRS/ETRRS [33] & No & $\begin{array}{l}\text { High (TRRS)/ } \\
\text { Lower(ETRRS) }\end{array}$ & Low & Medium & Yes \\
\hline UMB [34] & Yes & Medium & High (RTB/CTB) & High & Yes \\
\hline BROADCOMM [35] & Not mentioned & Low & Low & High & Not mentioned \\
\hline FB [36] & Yes & Medium & Low & Medium & Yes \\
\hline REAR [37] & No & Low & Low & Medium & Yes \\
\hline
\end{tabular}

In order to solve the issue of broadcast storm problem (redundancy, contention and broadcast packet collisions) which occur due to simultaneous warning message forwarding in VANETs traffic safety applications, Fogue et al [26] proposed a novel scheme called enhanced Message Dissemination based on Roadmaps (eMDR) protocol which was tested on a realistic simulation environments (VANET scenarios based on real city maps). Their proposed eMDR protocol is designed to mitigate the broadcast storm problem in real urban scenarios by increasing the percentage of informed vehicles and by reducing the notification time at the same time. However, eMDR [26] is practically suitable in low vehicle densities and may require enhancement to apply in high vehicle density scenarios, or high market penetration rates.

In what we could refer to as an improvement upon the previous work of Fogue et al [26], Sanguesa et al [27] proposed two warning message dissemination approaches for adverse vehicle densities which were demonstrated in different urban scenarios. The two proposed Message Broadcasting solutions in Vehicular Networks by these authors are called Neighbor Store and Forward (NSF) and Nearest Junction Located (NJL) scheme. While the eMDR scheme proposed by Fogue et al [26] is practically suitable in low vehicle densities, one of the solutions proposed by Sanguesa et al [27] (NJL scheme) is specifically designed for very high vehicle densities so as to maximize message delivery effectiveness, something difficult to achieve in adverse vehicle density scenarios. The proposed NJL scheme not only increases the percentage of informed vehicles through message broadcast technique but also reduced the number of messages up to $46.73 \%$ [27]. Other similar works studied include the further research carried out by Sanguesa et al [28], a Real-Time Adaptive Dissemination (RTAD) scheme for VANETs, two distinct protocols in [29], TRAck DEtection (TRADE) and Distance Defer Transmission (DDT) protocols, Optimized Dissemination of Alarm Messages (ODAM) [30], Smart Broadcast Algorithm (SBA) [31], Contention Based Dissemination (CBD) [32], Time Reservation-based Relay Node Selecting Algorithm (TRRS) and Enhanced TRRS (ETRRS) [33], Urban Multi-hop Protocol (UMB) [34], BROADCOMM [35], Fast Broadcast (FB) protocol [36], and REAR [37]. In Table IV, we present a brief comparison of some selected existing Message Broadcasting solutions in Vehicular Networks. The following criteria are used in our comparison: the technique used to ensure that there is high percentage of informed vehicles (retransmissions/rebroadcasting), redundancy, latency, delivery rate and memory requirement.

\subsection{VANETs ad-hoc routing protocols}

Much research has been carried out on the suitability of MANET routing protocols in VANETs as well as several other research surveys [38-41]. Contrarily, the frequent network partitioning (intermittent network connectivity) due to extremely dynamic topology and high mobility in VANET render MANET protocols unsuitable for vehicular communications. Moreover, the assumptions in MANET routing that end-to-end network connectivity can be established at all times, and that intermediate nodes between source and destination can always be found cannot hold in VANET.

Many more existing researches have considered the

TABLE V. COMPARATIVE REVIEW OF EXISTING AD-HOC ROUTING PROTOCOLS IN VANETS

\begin{tabular}{|l|l|l|l|}
\hline $\begin{array}{l}\text { Routing } \\
\text { protocols }\end{array}$ & $\begin{array}{l}\text { Routing } \\
\text { mechanism }\end{array}$ & Use case & Downsides \\
\hline GPRS & Unicast & Comparison with other VANET protocols & Low PDR \\
\hline AODV & Unicast & Performance evaluation in urban scenarios & Low PDR \\
\hline OLSR & Broadcast & Performance evaluation in urban scenarios & Low PDR \\
\hline VADD & Unicast & $\begin{array}{l}\text { Ensuring packet routing with guaranteed QoS } \\
\text { for VANET }\end{array}$ & $\begin{array}{l}\text { Increased end-to-end delay due to } \\
\text { incessant varying topology and traffic } \\
\text { density }\end{array}$ \\
\hline DSR & Unicast & Comparison with other VANET protocols & Low PDR \\
\hline A-STAR & Unicast & Reliable packet routing in urban scenario & $\begin{array}{l}\text { Increased end-to-end delay due to poor } \\
\text { packet routing paths }\end{array}$ \\
\hline DRG & Geocast & timely communication over large area & $\begin{array}{l}\text { Unsuitable especially for time-critical } \\
\text { safety packet transmission in highly } \\
\text { dynamic VANET environments }\end{array}$ \\
\hline PMB & Unicast & Dissemination of emergency messages & Increased end-to-end delay \\
\hline BROADCOMM & Broadcast & $\begin{array}{l}\text { Dissemination of emergency messages in } \\
\text { highways }\end{array}$ & $\begin{array}{l}\text { Only applicable to highway network } \\
\text { scenarios }\end{array}$ \\
\hline ROVER & Geocast & transmission reliability and end-to-end QoS & $\begin{array}{l}\text { Data traffic type and volume not } \\
\text { considered }\end{array}$ \\
\hline DV-CAST & Broadcast & $\begin{array}{l}\text { Designed for reliability and efficiency of } \\
\text { vehicular communication systems }\end{array}$ & $\begin{array}{l}\text { Built on the assumption that vehicles } \\
\text { can accurately detect the local }\end{array}$ \\
\hline
\end{tabular}




\begin{tabular}{|l|l|l|l|}
\hline & & & connectivity \\
\hline DOLPHIN & Broadcast & $\begin{array}{l}\text { Inter-vehicle communications technology for } \\
\text { group cooperative driving in highway } \\
\text { scenarios }\end{array}$ & $\begin{array}{l}\text { Overwhelming network loads which } \\
\text { leads to high network end-to-end delay }\end{array}$ \\
\hline MDDV & Unicast & Efficient and reliable data dissemination & $\begin{array}{l}\text { Increased network delay as traffic } \\
\text { density varies by time }\end{array}$ \\
\hline
\end{tabular}

effectiveness of conventional ad-hoc routing and MANET protocols for VANET environments. Performance analysis and evaluation of several conventional ad-hoc routing solutions such as Ad hoc On-Demand Distance Vector (AODV), Dynamic Source Routing (DSR) and Destination-Sequenced Distance-Vector Routing (DSDV) protocols for vehicular network scenarios have been presented by Xiong and $\mathrm{Li}$ [42]. The authors inferred that these MANET solutions are not effective in VANET scenarios. The results of their simulation experiments further showed that these traditional MANET protocols lead to increase of routing load over vehicular network which in turn reduce the overall packet delivery ratio (PDR) and increase network end-to-end delay.

Manvi et al [43] used a uniform distribution to generate node movement pattern which they used to carry out performance evaluation of the Optimized Link State Routing (OLSR) and AODV protocols. Haemi et al [44] also compared and evaluated the performance of AODV, DSR and Swarm intelligent based routing protocols. While their simulation results clearly show that SWARM intelligence based routing protocol has some exciting performance in vehicular network scenario in terms of throughput, data delivery cost, latency and data delivery ratio, the suitability of AODV and DSR protocols in VANET environment were not guaranteed.

The authors in [45] and [46] worked to improve and enhance existing MANET protocol (AODV) in order to make it suitable for vehicular communication systems. Their improved and enhanced routing protocols were called Position AODV (PAODV) and Direction AODV (DAODV) with improved and enhanced route stability and reduced overall network overhead. Their studies also show that more appropriate routes can be discovered with or without node mobility prediction. They showed that selecting fewer routes would help to mitigate both packet routing overhead on the network and network link breakage as opposed to AODV.

Naumov et al [47] studied the performance efficiency of AODV and GPRS over highway and urban scenarios using mobility information gathered from a microscopic vehicular traffic simulator based on real-life roadmaps of Switzerland. The results of their study showed that both AODV and General Packet Radio Service (GPRS) demonstrate grave performance limitations in terms of significantly reduced packet delivery ratio due to extremely high mobility of nodes. Table $\mathrm{V}$ shows the comparative review of evaluated ad-hoc routing protocols designed for vehicular communication systems such as mobility-centric data dissemination algorithm (MDDV) [48], anchor bus street and traffic-aware routing (ABSTAR) protocol [49], vehicle-assisted data delivery (VADD) [50], Dedicated Omni-purpose inter-vehicle communication Linkage Protocol for HIghway automation (DOLPHIN) for inter-vehicle communications system [51], Position-based multi-hop broadcast (PMB) [52], robust vehicular routing (ROVER) and distributed robust geocast
(DRG) protocols [53], BROADcast COMMunication (BROADCOMM) protocol [35], distributed vehicular broadcast (DV-CAST) [54].

Hence, where the aforementioned assumptions do not hold in VANET, the carry and forward approach was proposed in [55] for VANETs whereby a moving vehicle continuously carry a data packet until it is forwarded to another vehicle closer to the destination(s) in absence of any direct route.

The challenging issue of packet routing in VANETs could be resolved if the three main categories of VANETs routing algorithm such as geographic, opportunistic and trajectory-based forwarding [17] could be combined with the concept of carry and forward mentioned above to realize an optimum VANET routing solution in order to reduce the end-to-end delay as well as the total number of dropped data packets during routing. Future task could be to carry out an extensive experiments and simulations with more refined parameters and extension of existing routing protocols so as to overcome the problems of possible long end-to-end delay and high rate of packet drop during vehicular communications without drastic increment in network overhead.

\subsection{Congestion control techniques in inter-vehicle communication}

To achieve one of the key aims of VANETs, which is the current and future needs of reducing the number of occurrence of road traffic accidents as well as increasing traffic efficiency and safety on the motorways, cutting-edge research into vehicular safety communication systems must be pursued.

Realizing this feat means solving major technical challenges of congestion control for both periodic and emergency beacon broadcast and ensuring the reliability and scalability of safety messages transmission especially in congested situations. The design and development of efficient IEEE 802.11p-based DSRC wireless access system that will support efficient and reliable congestion control (CC) techniques is required for effective dissemination of time-critical safety messages in vehicular networks. Many studies have been carried out to validate and evaluate the performance of congestion control techniques [45-61]. Several approaches have been employed by researchers for performance evaluation of wireless communication systems such as vehicular wireless communication system with simulation and field test methodology as the two most widely used approaches. Virtually, the performance of all the existing studies on congestion control techniques in vehicular communications [56-57], [62-64] were validated and evaluated through simulation experiments as opposed to field test which involves high research costs especially with a high number of experimenting vehicles. Most of the recent proposed vehicular network solutions, protocols, schemes and frameworks reviewed in this paper share 
common approaches and methodologies in their investigations. Each of the works used mobile nodes which are configured according to the specifications of IEEE $802.11 \mathrm{p}$ standard, equipped with GPS receiver and share common IEEE $802.11 \mathrm{p} \mathrm{CCH}$. Similarly, in all of the reviewed works, time-sensitive safety messages are accorded higher priority over non safety related messages.

The performance parameters used in the reviewed works include message (safety message and beacon) reception rate, channel access delay, percentage of successful message reception (PSMR), channel busy ratio (CBR), percentage of message loss (PML), throughput, level of channel congestion (LCC), bit error ratio (BER), average transmission delay (ATD), channel busy fraction $(\mathrm{CBF})$, contention window $(\mathrm{CW})$ size, etc. The propagation loss models used were either Nakagami or TwoRayGround. The findings and results of existing works evaluation contained in Table $\mathrm{V}$ were summarized as follows.

i. From the review of existing works on congestion control algorithms in vehicular communication systems, one of the most widely used performance parameters is BER. It is also observed that the variation of $\mathrm{CW}$ shows little effect on BER. On the other hand, steep increase in CW size to CWmax leads to a long end-to-end delay [65].

ii. Most well-used network simulator in vehicular networks research community is NS-2 [57-64] with a mobility model called Simulation of Urban Mobility (SUMO) which is used to generate trajectories that are fed into NS-2 simulator to create mobility patterns for nodes movement.

iii. It is observed that Nakagami propagation model is well-used compared to other models. Most researchers deployed Nakagami fading model because of its generality compared to other propagation models like Rayleigh or Rician. Another reason is that Nakagami fading model can represent a wide range of fading situations, even probable conditions which are more severe compare to Rayleigh fading model. Nakagami's distribution is adjudged more suitable to vehicular networks than Rayleigh or log-normal shadowing model $[64,66]$.

The review also shows that WAVE-based MAC protocol performs poorly in multiple access coordination as channel load approaches the maximum channel capacity [67].

Several existing works investigated extensively how to improve reliability and efficiency in packet transmission by adjusting vehicle's transmission frequency or power, but these transmitter-based schemes depend on the vehicle's wireless radio hardware control and can be difficult to estimate the status of the expected receivers. These challenges were resolved by Schmidt et al [68] and Stanica et al [69] using receiver carrier sensing threshold control approach. In their separate studies, the receivers sense the $\mathrm{CCH}$ and adjust their states for the inbound transmissions. The merit of receiver carrier sensing threshold control approach is that it can be achieved through software as opposed to adjusting vehicle's transmission frequency or transmission power.

Table IV show the review of the performance evaluations of existing works on congestion control algorithms conducted through simulation using various network simulators and road traffic mobility models for vehicular movement pattern generation. However, the performance results obtained with the reviewed congestion control algorithms in Table IV show that the QoS requirements of safety VANET applications such as high reliability and low latency were not guaranteed by any of the reviewed algorithms. We pinpoint two major shortfalls found in the review of the evaluated works which must be tackled and improved in other to realize, develop and deploy vehicular communication systems to reduce the number of road traffic accidents occurrence.

Firstly, virtually most of the studies were conducted on a highway scenario except for the works of Fogue et al [26], Sanguesa et al [26-27] and Martinez et al [37]. However, urban and highway scenarios differ in features such as their movement patterns (or trajectories). Besides, homogeneous vehicular traffic densities are common in one-dimensional highways as opposed to two-dimensional urban vehicular scenarios [70]. Interestingly, as opposed to most of the works compared in Table VI [26-29][56-65, 68, 70], the works of Fogue et al [26], Sanguesa et al [27] and Martinez et al [37] carried out a simulation of real city maps with buildings using a modified NS-2 simulator to model the impact of distance and obstacles in signal propagation. The wireless Radio Propagation Model used is the Real Attenuation and Visibility Model (RAV) [37] [71], a model which proved to increase the level of realism in VANET simulations using real-life urban roadmaps as scenarios where buildings act as obstacles. This model implements the signal attenuation due to the distance between vehicles based on real data obtained from experiments in different streets of the cities of Valencia and Teruel in Spain. Their works considered VANETs protocols performance in urban scenarios, as well as different and non-homogeneous vehicular traffic densities in contrast to homogeneous vehicular traffic densities which are common in one-dimensional highway motorways. Additionally, other works that considered the performance of vehicular network protocols in urban scenarios, as well as in a non-homogeneous traffic densities as opposed to homogeneous vehicular traffic density include the reviewed work of Sanguesa et al [26] (see Table 6). The authors specifically studied the effectiveness of their two proposed frameworks (i.e. NSF and NJL) in an adverse (or varying) vehicular density scenarios.

Secondly, we recommend the use of network simulators and emulators that tightly combines both network simulation and vehicle traffic mobility simulation such as Veins [72], NCTUNS (EstiNet) [73] and iTETRIS [74]. Studies on congestion control algorithms/schemes should be conducted on these bi-directionally coupled network and road traffic simulation for improved inter-vehicle communications (IVC) analysis to achieve more realistic and close to real-life environment for effective VANET simulation.

\subsection{Power control and management}

Power management in the sense of energy efficiency is not an issue in VANETs as is the case with other evolving 
wireless technologies such as LTE due to the existence of installed batteries in the vehicles. However, power management in term of transmission (TX) power is a challenging issue that must be resolved to achieve effective vehicular communication. In a dense vehicular network, high TX power could lead to disruption of an ongoing transmission with another transmission at a distant vehicle as a result of interferences. For this reason, reduced TX power should be used in a denser network to achieve reliable and efficient transmission.

Efficient routing could as well be achieved through proper adjustment of the TX power to increase the overall throughput and reduce interference occurrences. So far, very few algorithms have been proposed in this regard. One such algorithm proposed in [75] adjusts the TX power to limit the total number of transmitting neighbors within the maximum and minimum TX thresholds.

\subsection{Security, privacy, anonymity and liability}

Security is one of the challenges that demands careful attention prior to designing and deployments of VANETs in our motorways. Several potential threats to vehicular communication system exist, ranging from fake (or fraudulent) messages capable of disrupting traffic or even causing danger to driver's privacy invasion. Frameworks must be worked out to enable vehicles receiving data packets from other vehicles (or network nodes) to be able to establish trust on the entities transmitting the packets while the privacy of the drivers are protected using anonymous node identities. Though, the major challenge of security and privacy in VANET is how to develop a security solution capable of supporting the tradeoff between authentication, liability, and privacy given that every vehicular information (both safety and non-safety related information) must be disclosed to appropriate governmental agencies (transport authority) by the network. However, such security solution must make vehicle identification or tracking impossible especially for non-trusted parties. In line with the above line-of-thought, $\mathrm{SeVeCOM}$, as presented in [76-77] has provided a security architecture that is used as input for security related European Telecommunications Standards Institute (ETSI) [19] ITS WG5 and ISO CALM standards. Fig. 3 depicts the WAVE protocol stack showing IEEE 1609.2 security service protocol residing at the lower layer

\subsection{Reliability and cross-layer approach between transport layer and network layer}

Vehicle to vehicle (or inter-vehicle) communication network is associated with the problem of incessant network route break-up leading to erroneous message transmission due to the wireless nature of the VANET environment. This issue gives rise to the challenge of reliability in vehicular communication networks. Several error recovery techniques have been proposed and implemented over the years to achieve reliable transfer of packets in wireless communications with respect to vehicular communication systems. Traditional techniques such as Automatic Repeat reQuest (ARQ) [78] and Forward Error Correction (FEC) [79] could not yield the desired results in vehicular communication yet. ARQ can only be used to ensure reliability in point-to-point unicast communication. Unlike FEC that works with readily awaiting streams of packets, each vehicle creates packet periodically or automatically in the face of emergency and broadcast to other vehicles. Hence, the issue of broadcast communication reliability remains an open research challenge in the design and deployment of VANET. Consequently, for reliable and efficient vehicular communication networks to be achieved on top of the inherently unreliable wireless network, effective and competent loss packets recovery schemes are required. Designing cross-layer medium access control (MAC) that will span across network (routing) layer and transport layer to support real-time services and multimedia applications can be of immense benefit in vehicular communication networks.

\subsection{V2X video delivery}

In VANETs, video communication offers a significant contribution to quality of experience $(\mathrm{QoE})$ for both the drivers, passengers and pedestrians on the road. Additionally, video transmission is bit loss tolerant. Hence, the loss of one packet may not affect the experience of users [80]. Therefore, video communication has potential to be of high benefit for traffic management as well as for providing value-added entertainment [81] and advertising services [82]. In vehicular networks, vast literatures exist on the study of transmission technologies for video streaming on both MAC and network layers [83-90]. Several studies on performance of video streaming in IEEE $802.11 \mathrm{p}$ vehicular networks have been carried out on MAC layer [91-93]. Over the network layer, Bradai and Ahmed [94] presented a rebroadcast mechanism while Rezende et al. [95] study the relay node selection algorithm. As more and more vehicles are equipped with wireless communication devices, large number of users expect to be serviced with high QoE in V2X live video content delivery.

Therefore, not only the video delivery approach but also the video source selection scheme should be extensively studied. However, the high mobility and the frequently changing topology of VANET nodes make the selection of video source an impediment to efficient and reliable video delivery. Selection of unsuitable provider may lead to incessant interruptions of communications causing frequent video fragmentations and transmission of invalid video fragments would also lead to unavoidable wastage of valuable communication bandwidth. Yun et al [96] addressed part of this challenge in their proposed novel video source decision scheme called Cluster and Dynamic Overlay based video delivery over VANETs (CDOV). In their research, they used an on-demand clustering approach where vehicles with the same video requirement/supply and moving features form clusters. Using this approach, an overlay tree will be constructed dynamically inside the cluster based on the relation between supply and demand in which all requesters can find their greedy optimal source easily. Furthermore, the head-RSU communication and the intra-cluster communication are designed for video streaming over this network structure. 
Table VI. Review of previous works on congestion control techniques in inter-vehicle communication

\begin{tabular}{|c|c|c|c|c|c|c|c|}
\hline Algorithms/Schemes & $\begin{array}{l}\text { Variation } \\
\text { factors }\end{array}$ & $\begin{array}{l}\text { Traffic } \\
\text { scenario }\end{array}$ & $\begin{array}{l}\text { Network } \\
\text { simulator }\end{array}$ & $\begin{array}{l}\text { Mobility } \\
\text { Generator }\end{array}$ & $\begin{array}{l}\text { Application } \\
\text { type }\end{array}$ & $\begin{array}{l}\text { Propagation } \\
\text { loss model }\end{array}$ & $\begin{array}{l}\text { Performance } \\
\text { parameters }\end{array}$ \\
\hline $\begin{array}{l}\text { Message } \\
\text { dissemination } \\
\text { scheme [26] }\end{array}$ & $\begin{array}{l}\text { Different } \\
\text { vehicle } \\
\text { densities }\end{array}$ & Urban & NS-2 & SUMO & $\begin{array}{l}\text { Safety and } \\
\text { periodic } \\
\text { message }\end{array}$ & $\begin{array}{l}\text { Real } \\
\text { Attenuation and } \\
\text { Visibility } \\
\text { Model (RAV) } \\
{[37][71]}\end{array}$ & $\begin{array}{l}\text { Informed } \\
\text { vehicles (\%), } \\
\text { Notification } \\
\text { time, } \\
\text { Delivery rate } \\
\end{array}$ \\
\hline $\begin{array}{l}\text { Neighbor Store and } \\
\text { Forward (NSF) and } \\
\text { Nearest Junction } \\
\text { Located (NJL) [27] }\end{array}$ & $\begin{array}{l}\text { Different } \\
\text { vehicle } \\
\text { densities }\end{array}$ & Urban & NS-2 & $\begin{array}{l}\text { CityMob } \\
\text { (based on } \\
\text { SUMO) }\end{array}$ & $\begin{array}{l}\text { Warning/Safety } \\
\text { and periodic } \\
\text { message }\end{array}$ & RAV & $\begin{array}{l}\text { Message } \\
\text { delivery rate }\end{array}$ \\
\hline $\begin{array}{l}\text { RTAD: Real-time } \\
\text { adaptive } \\
\text { dissemination system } \\
{[28]}\end{array}$ & $\begin{array}{l}\text { Different } \\
\text { vehicle } \\
\text { densities }\end{array}$ & Urban & NS-2 & $\begin{array}{l}\text { CityMob } \\
\text { (based on } \\
\text { SUMO) }\end{array}$ & Safety message & RAV & $\begin{array}{l}\text { Informed } \\
\text { vehicles (\%), } \\
\text { Notification } \\
\text { time, } \\
\text { Delivery rate } \\
\end{array}$ \\
\hline $\begin{array}{l}\text { Topology-based } \\
\text { Visibility scheme } \\
{[29]}\end{array}$ & $\begin{array}{l}\text { Node } \\
\text { densities, }\end{array}$ & Urban & NS-2 & SUMO & $\begin{array}{l}\text { Warning/Safety } \\
\text { and periodic } \\
\text { message }\end{array}$ & $\begin{array}{l}\text { Obtained } \\
\text { directly from } \\
\text { experimental } \\
\text { data }\end{array}$ & $\begin{array}{l}\text { Packet error } \\
\text { rate (PER), } \\
\text { Packet } \\
\text { delivery rate }\end{array}$ \\
\hline $\begin{array}{l}\text { Dynamic/Distributed } \\
\text { Channel Congestion } \\
\text { Control [56] }\end{array}$ & $\begin{array}{l}\text { Transmission } \\
\text { rate, channel } \\
\text { load }\end{array}$ & $\begin{array}{l}\text { Highway } \\
\text { lanes }\end{array}$ & $\begin{array}{l}\text { Not } \\
\text { mentioned }\end{array}$ & $\begin{array}{l}\text { Not } \\
\text { mentioned }\end{array}$ & $\begin{array}{l}\text { Safety and } \\
\text { periodic } \\
\text { message } \\
\end{array}$ & Nakagami & $\begin{array}{l}\text { PSMR, PML, } \\
\text { LCC, BER }\end{array}$ \\
\hline $\begin{array}{l}\text { Avoiding Information } \\
\text { Congestion [57] }\end{array}$ & $\begin{array}{l}\text { Signal to } \\
\text { interference } \\
\text { plus noise } \\
\text { ratio (SINR) }\end{array}$ & $\begin{array}{l}\text { Highway } \\
\text { lanes }\end{array}$ & $\begin{array}{l}\text { MATLAB } \\
\text { and NS-2 }\end{array}$ & Vanetmobisim & Safety message & TwoRayGround & $\begin{array}{l}\text { Throughput, } \\
\text { average } \\
\text { transmission } \\
\text { delay, BER }\end{array}$ \\
\hline $\begin{array}{l}\text { Scheme for collision } \\
\text { avoidance }[58]\end{array}$ & $\begin{array}{l}\text { Hop count, } \\
\text { node density }\end{array}$ & $\begin{array}{l}\text { Highway } \\
\text { lanes }\end{array}$ & $\begin{array}{l}\text { NS-2 and } \\
\text { MATLAB }\end{array}$ & $\begin{array}{l}\text { Not } \\
\text { mentioned }\end{array}$ & Safety message & Not mentioned & $\begin{array}{l}\text { BER, } \\
\text { End-to-end } \\
\text { Delay } \\
\end{array}$ \\
\hline $\begin{array}{l}\text { Safety context-aware } \\
\text { congestion control } \\
{[59]}\end{array}$ & $\begin{array}{l}\text { Tx power, } \\
\text { packet size, } \\
\text { channel }\end{array}$ & $\begin{array}{l}\text { Highway } \\
\text { lanes }\end{array}$ & NS-2 & $\begin{array}{l}\text { Not } \\
\text { mentioned }\end{array}$ & $\begin{array}{l}\text { Safety-critical } \\
\text { message }\end{array}$ & Nakagami & $\begin{array}{l}\text { Throughput, } \\
\text { Packets } \\
\text { received }\end{array}$ \\
\hline $\begin{array}{l}\text { VANET Channel } \\
\text { Congestion Control } \\
{[60]}\end{array}$ & $\begin{array}{l}\text { Packet size, } \\
\text { density, } \\
\text { channel }\end{array}$ & $\begin{array}{l}\text { Highway } \\
\text { lanes }\end{array}$ & NS-2 & SUMO & Safety message & Nakagami & $\begin{array}{l}\text { Packet error } \\
\text { ratio, BER }\end{array}$ \\
\hline $\begin{array}{l}\text { Congestion control } \\
\text { for DSRC systems } \\
{[61]}\end{array}$ & $\begin{array}{l}\text { Network } \\
\text { density, } \\
\text { channel } \\
\text { noise }\end{array}$ & $\begin{array}{l}\text { Highway } \\
\text { lanes }\end{array}$ & NS-2 & $\begin{array}{l}\text { Not } \\
\text { mentioned }\end{array}$ & Safety message & Not mentioned & $\begin{array}{l}\text { Channel } \\
\text { Busy } \\
\text { Fraction } \\
(\mathrm{CBF})\end{array}$ \\
\hline $\begin{array}{l}\text { LIMERIC: Algorithm } \\
\text { for DSRC } \\
\text { Congestion Control } \\
{[62]}\end{array}$ & $\begin{array}{l}\text { Network } \\
\text { density, } \\
\text { channel } \\
\text { noise } \\
\end{array}$ & $\begin{array}{l}\text { Highway } \\
\text { lanes }\end{array}$ & $\begin{array}{l}\text { MATLAB } \\
\text { and NS-2 }\end{array}$ & $\begin{array}{l}\text { Not } \\
\text { mentioned }\end{array}$ & Safety message & Not mentioned & $\begin{array}{l}\text { Channel } \\
\text { Busy } \\
\text { Fraction } \\
\text { (CBF) } \\
\end{array}$ \\
\hline $\begin{array}{l}\text { Congestion Control } \\
\text { Schemes in VANETs } \\
{[63]}\end{array}$ & $\begin{array}{l}\text { Node } \\
\text { density, Tx } \\
\text { power } \\
\end{array}$ & $\begin{array}{l}\text { Highway } \\
\text { lanes }\end{array}$ & $\begin{array}{l}\text { NS-3 and } \\
\text { MATLAB }\end{array}$ & SUMO & $\begin{array}{l}\text { Safety and } \\
\text { periodic } \\
\text { message }\end{array}$ & Nakagami & $\begin{array}{l}\text { Channel } \\
\text { Busy Ratio } \\
(\mathrm{CBR}) \\
\end{array}$ \\
\hline $\begin{array}{l}\text { Beacon Congestion } \\
\text { Control Algorithms } \\
\text { [64] }\end{array}$ & $\begin{array}{l}\text { Tx power, } \\
\text { frequency, } \\
\text { density }\end{array}$ & Urban & NS-2 & $\begin{array}{l}\text { Not } \\
\text { mentioned }\end{array}$ & $\begin{array}{l}\text { Safety and } \\
\text { periodic } \\
\text { message }\end{array}$ & Nakagami & BER, (CBR) \\
\hline $\begin{array}{l}\text { Contention window } \\
\text { analysis [65] }\end{array}$ & $\begin{array}{l}\text { CW size, Tx } \\
\text { frequency, } \\
\text { density } \\
\end{array}$ & $\begin{array}{l}\text { Highway } \\
\text { lanes }\end{array}$ & $\mathrm{OMNeT}++$ & $\begin{array}{l}\text { MiXiM } \\
\text { framework }\end{array}$ & $\begin{array}{l}\text { Periodic } \\
\text { message }\end{array}$ & Not mentioned & $\begin{array}{l}\text { BER, delay, } \\
\text { inter-arrival } \\
\text { time }\end{array}$ \\
\hline $\begin{array}{l}\text { Transmit power } \\
\text { control for } \\
\text { safety-critical } \\
\text { messages }[68,70]\end{array}$ & $\begin{array}{l}\text { Tx power, } \\
\text { channel }\end{array}$ & $\begin{array}{l}\text { Highway } \\
\text { lanes }\end{array}$ & NS-2 & $\begin{array}{l}\text { Not } \\
\text { mentioned }\end{array}$ & $\begin{array}{l}\text { Safety and } \\
\text { periodic } \\
\text { message }\end{array}$ & Nakagami & $\begin{array}{l}\text { BER, delay, } \\
\text { Channel } \\
\text { access time }\end{array}$ \\
\hline
\end{tabular}




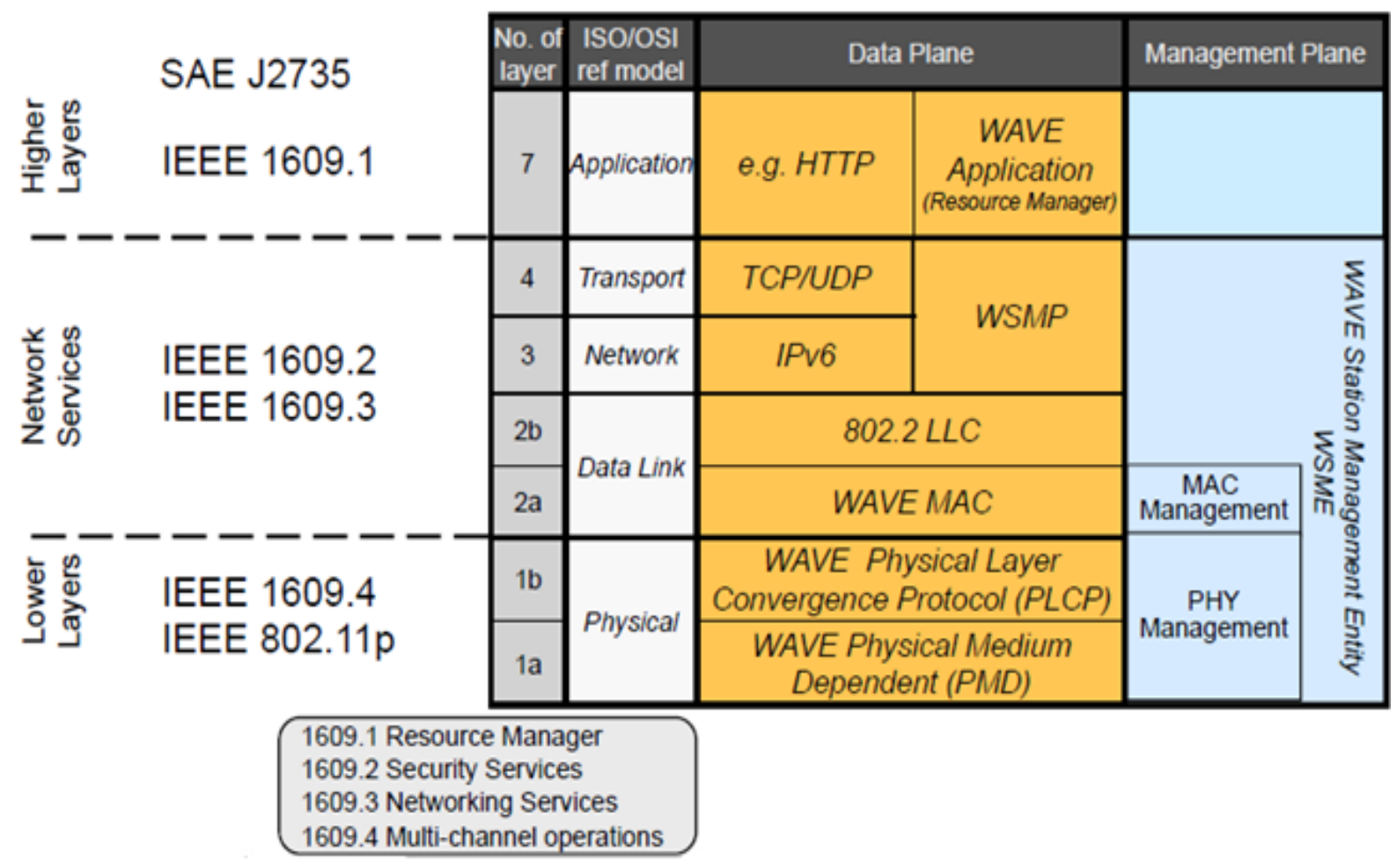

Fig. 3 WAVE protocol stack showing IEEE 1609.2 security service protocol residing at the lower layer.

Live V2X video delivery over VANETs is an efficient way to improve the applications in both safety and infotainment. However, the characteristics of VANETs such as frequent network disconnection, high mobility of vehicles, dynamic topology, interactive requirements, and limited number of infrastructures pose great challenges for live V2X video delivery in VANETs.

\subsection{V2X multi-channel operation}

VANETs rely on a multi-channel operational mechanism to support V2X communications. Multiple service channels (SCHs) are assigned in the $5 \mathrm{GHz}$ spectrum for non-safety data transfer, while a unique control channel $(\mathrm{CCH})$ is used for broadcasting basic safety messages and service advertisements at regular intervals. Single-radio WAVE devices stay tuned on one radio channel at a time and alternately switch between channels to monitor safety messages and to access information and entertainment services; while dual-radio devices can simultaneously stay tuned on both types of channels. Multi-channel coordination, synchronization, and access are big challenges in VANETs; many design choices are still open challenges in both ETSI and IEEE standardization bodies.

In order to support both safety-related and non-safety applications in vehicular communication networks, IEEE 1609.4 protocol [97] (see Figure 2) defines a channel switching mechanism to enable a single WAVE radio to operate efficiently on multiple channels. IEEE 1609.4 is a functional extension of IEEE 802.11e MAC [98] to enable multi-channel coordination whose functions include efficient channel routing, data buffers (queues), prioritization, and channel coordination.
Though the availability of multiple channels is beneficial in terms of throughput performance [99], the multi-channel organization in the dynamic vehicular communications environment raises several challenges. In reality, VANET characteristics, such as the heterogeneous nature and requirements of vehicular applications, the absence of central coordination, the unstable, distributed, and frequently changing nature of wireless links (network topology), undeniably challenge the coordination of multi-channel activities. To concurrently support safety and non-safety applications, single-radio devices may periodically and synchronously switch between $\mathrm{CCH}$ and SCHs, according to rules defined by the IEEE 1609.4 standard [100], whereas dual-radio devices, as considered by ETSI [101], could have one radio tuned to the $\mathrm{CCH}$ and the second radio tunable to one of the available SCHs. WAVE dual-radio devices promise better spectral efficiency but at the expense of a higher level of implementation complexity. However, considering the cross-channel interference issues, the V2X multi-channel operation still has its own challenges that must be adequately resolved.

Although a plethora of researches have been published in the recent years on vehicular networks, very few of them actually addressed the V2X multi-channel operation defined for the frequency spectrum reserved for ITS by the IEEE 1609.4 standard. In VANETs, one of the primary issues is Medium Access Control (MAC), which aims to utilize the radio spectrum efficiently, so as to resolve potential contention and collision among vehicles for using the medium since contention reduces the performance of single channel MAC layer. Therefore, multi-channel MAC protocols are useful to provide better quality of services (QoS) because V2X multi-channel 
interference is a major problem when it comes to channel assignment.

Amongst the few research efforts that have been recorded in this area by different scholars including the works of Campolo et al [102], Yin et al [103] and several other related literatures [104-109]. Yunpeng et al [110] proposed a novel MAC protocol called Vehicular MESH Network (VMESH) which is a compliant of WAVE multi-channel operation system and based on a distributed beaconing scheme. VMESH divides the $\mathrm{CCH}$ into Beacon Period (BP) and the Safety Period (SP). In each Beacon period all vehicles can transmit a beacon packet which contains information for making dynamic resource reservation on SCHs. The proposed protocol provides contention free access on SCHs to improve the throughput of non-safety applications. This protocol dynamically adjusts the $\mathrm{CCH}$ based on density of vehicles to offer supports for safety applications and limits the available share for non-safety applications by the long $\mathrm{CCH}$ interval In line with [111], Mak et al [112] proposed a centralized MAC protocol called Dedicated Coordinating Access Point (DCAP) to enable V2X multi-channel operation for DSRCs. Each DCAP contains a Coordinating Access Point (CAP) and one or more Service Access Points (SAP) to provide non-safety applications in the region. Their proposed protocol divides time into periodic regulated intervals, called the repetition period. The length (L) of repetition period is determined by the maximum tolerable delay of safety messages. Each repetition period is further divided into two distinct sub periods: contention free period (CFP) and contention period (CP). In CFP, DCAP sends a broadcast packet to access the channel and polls each vehicle individually to transmit its safety messages, where remaining vehicles must remain silent. The nodes that are not polled in the CFP will eventually contend the channel in the following CP. This protocol permits vehicles to transmit only one safety message per CFP. DCAP avoids channel interference during the CFP by partitioning the communication range of control channel radio into multiple different radiuses of circular regions with a center at the CAP.

Campolo et al [105] presented a detailed analytical model validated with an event-driven custom simulation program that closely follows the IEEE 802.11 p protocol specifications and implemented in MatLab. Their analytical model was designed for the characterization of the losses of broadcast packets in IEEE 802.11p/WAVE vehicular networks by explicitly accounting for the WAVE channel switching. Even though the WAVE channel switching can have adverse effect on the general network performance, it has not been widely investigated in the literature except this research carried out by Campolo et al [105]. In their work, broadcast packets loss probabilities were derived as a function of contention window $(\mathrm{CW})$ size, number of nodes and WAVE channel errors. The results obtained clearly show that the IEEE $802.11 \mathrm{p} /$ WAVE standard fails to guarantee high reliability for packet broadcast transmissions and such is especially true when the sizes of CW of the IEEE 802.11p/WAVE standard are used, as a result of frame collisions synchronization events occurring at the beginning of the $\mathrm{CCH}$ interval. Although collisions can be reduced by increasing CWs size, it will be achieved at the detriment of broadcast packet losses due to channel switching at the end of the $\mathrm{CCH}$ interval. In order to solve this challenge, Campolo et al [105] recommended the use of shorter frames to reduce the impact of broadcast packet losses due to switching and channel induced errors. However, how to improve the reliability of WAVE service Advertisements (WSAs) was identified as a critical open research issue that require further analytical investigation to facilitate wider application and deployment of IEEE 802.11p/WAVE standard.

\section{Conclusions}

VANET is no longer a remote feasibility, given that heavy investments are already in the pipeline from several sectors including government agencies, auto-mobile industries, navigation safety and public transport authorities. VANET potentials, areas of application and prospects are growing rapidly including several kinds of services with multiple requirements and goals. However, several unique, novel open research challenges ranging from wireless network evolution, reliable message dissemination to event detection are making research in VANETs very attractive.

Many key important topics in vehicular communication are currently under intensive research and discussion. These topical issues include potential modification, refinement, enhancement and implementation of IEEE $802.11 \mathrm{p}$, wireless access in vehicular environment standard (WAVE), allocation of protected frequency band for mobile vehicular safety communication, integration (or unification) of different wireless technologies, congestion control, data security and transport, reliability in V2V communication and so on. The final step would be the harmonization of these promising solutions with other emerging worldwide vehicular communication projects and standards.

Different appropriate governmental agencies are working closely with car manufacturers/industries such as Mercedes, Toyota, BMW, Fiat, Nissan, Ford, etc to put prototype of Wi-Fi (IEEE $802.11 \mathrm{a} / \mathrm{b} / \mathrm{g} / \mathrm{n}$ ) and DSRC (IEEE 802.11p) equipped vehicles and other wireless access technology enabled vehicles on our motorways within the nearest possible future. Besides the recent technical development, another critical and important phase that will drive this new technology to success is systematic commercial market introduction and public acceptance.

\section{Conflict of Interest}

The authors declare that there is no conflict of interests regarding the publication of this paper.

\section{Acknowledgements}

This work is supported by a Grant-in-Aid for Scientific Research from Ebonyi State Government (EBSG) (No. EBSG/SSB/PS/VOL/VII/105). The authors would like to thank EBSG for the financial support as well as the anonymous reviewers for their critical reading, priceless comments, constructive criticism and suggestions which 
have undeniably improved quality of the paper.

\section{References}

[1] F. Bai and H. Krishnan, "Reliability Analysis of DSRC Wireless Communication for Vehicle Safety Applications," in Intelligent Transportation Systems Conference, 2006. ITSC '06. IEEE, Toronto, Ont., Sept. 2006.

[2] M. Moharrum and A. Al-Daraiseh, "Toward Secure Vehicular Ad-hoc Networks: A Survey," IETE Technical Review (Medknow Publications \& Media Pvt. Ltd.), vol. 29, no. 1, pp. 80-89, Jan/Feb 2012

[3] Y. Toor, P. Muhlethaler and A. Laouiti, "Vehicle Ad-Hoc networks: applications and related technical issues," Communications Surveys \& Tutorials, IEEE, vol. 10, no. 3, pp. 74 - 88, Third Quarter 2008.

[4] E. C. Eze; Sijing Zhang; Enjie Liu, "Vehicular Ad-Hoc networks (VANETs): Current state, challenges, potentials and way forward," 2014 20th International Conference on Automation and Computing (ICAC), pp.176-181, 12-13 Sept. 2014.

[5] Kenney, J.B., "Dedicated Short-Range Communications (DSRC) Standards in the United States," Proceedings of the IEEE, vol.99, no.7, pp.1162-1182, July 2011

[6] H. Krishnan, "Vehicle Safety Communications Project," 15 February 2006. [Online]. Available: http://www.sae.org /events/ads/krishnan.pdf. [Accessed 13-04-2015]

[7] A. Amditis, E. Bertolazzi, M. Bimpas, F. Biral, P. Bosetti, M. Da Lio,, L. Danielsson, A. Gallione, H. Lind, A. Saroldi and A. Sjögren, "A Holistic Approach to the Integration of Safety Applications: The INSAFES Subproject Within the European Framework Programme 6 Integrating Project PReVENT," IEEE Transactions on Intelligent Transportation Systems, vol. 11, no. 3, pp. 554-566, Sept. 2010.

[8] Y. Liu, J. Bi and J. Yang, "Research on Vehicular Ad-Hoc Networks," in Control and Decision Conference, 2009. CCDC '09. Chinese, Guilin, 17-19 June 2009.

[9] "Initernet ITS Consortium," [Online]. Available: http://www.internetits.org/ [Accessed 13-04-2015]

[10] A. Takahashi and N. Asanuma, "Introduction of Honda ASV-2 (advanced safety vehicle-phase 2)," in Intelligent Vehicles Symposium, 2000. IV 2000. Proceedings of the IEEE, Dearborn, MI, 2000.

[11] W. W. R. F. (WWRF), Technologies for the Wireless Future, vol. 3, K. David, Ed., Chichester, West Sussex: John Wiley \& sons LTD, 2008.

[12] "Vehicle Infrastructure Integration (VII) program of US Federal and State departments of transportation (DOT's) and automobile manufacturers.," 7 January 2014. [Online]. Available: http://www.vehicle-infrastructure.org/, http://w ww.its.dot.gov/press_room.htm. [Accessed 5 April 2014]

[13] F. Kargl, P. Papadimitratos, L. Buttyan, M. Müter, B. Wiedersheim, E. Schoch, T.-V. Thong, G. Calandriello, A. Held, A. Kung and J.-P. Hubaux, "Secure Secure Vehicular Communications: Implementation, Performance, and Research Challenges," IEEE Communications Magazine, vol. 46, no. 11, pp. 110-118, November 2008

[14] D. Abusch-Magder, P. Bosch, T.-E. Klein, P. A. Polakos, L. G. Samuel and H. Viswanathan, "911-NOW: A network on wheels for emergency response and disaster recovery operations," Bell Labs Technical Journal, vol. 11, no. 4, pp. 113-133, Winter 2007 (current version: April 2014)

[15] M. Alsabaan, W. Alasmary, A. Albasir and K. Naik,
"Vehicular Networks for a Greener Environment:A Survey," IEEE Communications Surveys \& Tutorials, vol. 15, no. 3, pp. 1372-1388, Third Quarter 2013.

[16] S. Zeadally, R. Hunt, Y.-S. Chen, A. Irwin and A. Hassan, "Vehicular Ad-Hoc networks (VANETS): status, results, and challenges," Telecommunication Systems, vol. 50, no. 4, pp. 217-241, August 2012.

[17] J. Jakubiak and Y. Koucheryavy, "State of the Art and Research Challenges for VANETs," in Consumer Communications and Networking Conference, 2008. CCNC 2008. 5th IEEE, Las Vegas, NV, Jan. 2008.

[18] H. Hartenstein and K. P. Laberteaux, "A tutorial survey on vehicular Ad-Hoc networks," Communications Magazine, vol. 46, no. 6, pp. 164-171, June 2008.

[19] G. Karagiannis, O. Altintas, E. Ekici, G. Heijenk, B. Jarupan, K. Lin and T. Weil, "Vehicular Networking: A Survey and Tutorial on Requirements, Architectures, Challenges, Standards and Solutions," Communications Surveys \& Tutorials, vol. 13, no. 4, pp. 584-616, Fourth Quarter 2011.

[20] M. L. Sichitiu and M. Kihl, "Inter-Vehicle Communication Systems: A Survey," Communications Surveys \& Tutorials, vol. 10, no. 2, pp. 88-105, 2008.

[21] European Commission, DG INFSO, INFSO G4/JJ D(2006) 701311 Working Paper on Intelligent Co-operative Systems based on V2V and V2I Communications, Jan. 2006

[22] Y. Luo, W. Zhang and Y. Hu, "A New Cluster Based Routing Protocol for VANET," in Networks Security Wireless Communications and Trusted Computing (NSWCTC), 2010 Second International Conference on Networks Security, Wuhan, Hubei, April 2010.

[23] N. Maslekar, M. Boussedjra, J. Mouzna and L. Houda, "Direction based clustering algorithm for data dissemination in vehicular networks," in Vehicular Networking Conference (VNC), Tokyo, Oct. 2009.

[24] Y. Fan, T. Yuliang and H. Lianfen, "A novel cooperative MAC for broadcasting in clustering VANETs," in 2013 International Conference on Connected Vehicles and Expo (ICCVE), Las Vegas, NV, Dec. 2013.

[25] B. K. Chaurasia, R. S. Tomar, S. Verma and G. S. Tomar, "Suitability of MANET Routing Protocols for Vehicular Ad-Hoc Networks," in 2012 International Conference on Communication Systems and Network Technologies (CSNT), Rajkot, May 2012.

[26] Fogue, P. Garrido, F. J. Martinez, J.-C. Cano, C. T. Calafate, and P. Manzoni. "Evaluating the impact of a novel message dissemination scheme for Vehicular Networks using real maps", Transportation Research Part C: Emerging Technologies, vol. 25, pp. 61-80. December, 2012.

[27] Sanguesa J., Fogue M., Garrido P., Martinez F. J., Cano J.-C., and Calafate C. T. "Using Topology and Neighbor Information to Overcome Adverse Vehicle Density Conditions" Transportation Research, Part C: Emerging Technologies, vol. 42, pp. 1-13. May 2014.

[28] Sanguesa J., Fogue M., Garrido P., Martinez F. J., Cano J.-C., Calafate C. T., and Manzoni P. "RTAD: a Real-time Adaptive Dissemination System for VANETs" Computer Communications. vol. 60, pp. 53-70. April 2015.

[29] Min-Te Sun; Wu-chi Feng; Lai, Ten-Hwang; Yamada, K.; Okada, H.; Fujimura, K., "GPS-based message broadcast for adaptive inter-vehicle communications," IEEE-VTS Fall VTC 2000. 52nd Vehicular Technology Conference, 2000, vol.6, no., pp.2685-2692 vol.6, 2000.

[30] Benslimane A. Optimized Dissemination of Alarm Messages in Vehicular Ad-hoc Networks (VANET), High Speed 
Networks and Multimedia Communications, Springer, Volume 3079, pp 655-666, 2004.

[31] Fasolo E., Furiato R., and Zanella A. Smart Broadcast algorithm for inter-vehicular communications, in Proc. of the Wireless Personal Multimedia Communication (WPMC'05), IWS 2005, September 2005.

[32] Torrent-Moreno, M., "Inter-vehicle communications: assessing information dissemination under safety constraints," Fourth Annual Conference on Wireless on Demand Network Systems and Services, 2007. WONS '07, pp.59-64, 24-26 Jan. 2007.

[33] Kim T., Hong W., and Kim H. An effective Multi-hop Broadcast in Vehicular Ad-hoc Network, in Proc. of the Architecture of Computing Systems (ARCS 2007), March 2007.

[34] Korkmaz G., and Ekici E., Urban Multi-hop Broadcast Protocol for Inter-Vehicle Communication Systems, in Proc. of the 1st ACM workshop on vehicular Ad-Hoc networks (VANET'04), October 2004.

[35] Durresi M., Durresi A., and Barolli L., Emergency Broadcast Protocol for Inter-Vehicle Communications, in Proc. of the 11th International Conference on Parallel and Distributed Systems (ICPADS'05), 2005.

[36] Plazzi C., Ferretti S., Roccetti M., Pau G., and Gerla M. How Do You Quickly Choreograph Inter-Vehicular Communications? A Fast Vehicleto-Vehicle Multi-Hop Broadcast Algorithm, Explained, in Proc. of the 4th IEEE Consumer Communications and Networking Conference (CCNC 2007), January 2007.

[37] Hao Jiang; Hao Guo; Lijia Chen, "Reliable and Efficient Alarm Message Routing in VANET," 28th International Conference on Distributed Computing Systems Workshops, 2008. ICDCS '08, pp.186-191, 17-20 June 2008.

[38] S. N. Mohammad, M. J. Ashraf, S. Wasiq, S. Iqbal and N. Javaid, "Analysis and Modeling of Network Connectivity in Routing Protocols for MANETs and VANETs," in 2013 Eighth International Conference on Broadband and Wireless Computing, Communication and Applications (BWCCA), Compiegne, Oct. 2013

[39] P. Singh, "Comparative study between unicast and Multicast Routing Protocols in different data rates using vanet," in 2014 International Conference on Issues and Challenges in Intelligent Computing Techniques (ICICT), Ghaziabad, Feb. 2014. [40] H. L. Sharma, P. Agrawal and R. V. Kshirsagar, "Acute direction route node selection multipath routing for VANET: Design approach," in 2014 International Conference on Signal Processing and Integrated Networks (SPIN), Noida, Feb. 2014.

[41] Z. D. Chen, H. Kung and D. Vlah, "Ad-Hoc Relay Wireless Networks over Moving Vehicles on Highways," in MobiHoc '01 Proceedings of the 2nd ACM international symposium on Mobile Ad-Hoc networking \& computing, New York, NY, USA, 2001

[42] X. Wei, L. Qing-Quan, Performance Evaluation of Data Disseminations for Vehicular Ad-Hoc Networks in Highway Scenarios, http://www.isprs.org/congresses/proceedings/1pdf/17 4.pdf, [Accessed 13-04-2015]

[43] Manvi, S.S.; Kakkasageri, M.S.; Mahapurush, C.V., "Performance Analysis of AODV, DSR, and Swarm Intelligence Routing Protocols In Vehicular Ad-Hoc Network Environment," International Conference on Future Computer and Communication, 2009. ICFCC 2009, pp.21-25, April 2009

[44] Haemi, J.; Fiore, M.; Filali, F.; Bonnet, C., "A Realistic Mobility Simulator for Vehicular Ad-Hoc Networks", EURECOM Technical Report, 2007 Available at: http://www.eurecom.fr/util/ publidownload.en.htm?id=1811, [Accessed 13-04-2015]
[45] Abedi, O.; Berangi, R.; Azgomi, M.A., "Improving Route Stability and Overhead on AODV Routing Protocol and Make it Usable for VANET," 29th IEEE International Conference on Distributed Computing Systems Workshops, 2009. ICDCS Workshops '09. pp.464-467, June 2009

[46] Abedi, O.; Fathy, M.; Taghiloo, J., "Enhancing AODV routing protocol using mobility parameters in VANET," IEEE/ACS International Conference on Computer Systems and Applications, 2008. AICCSA 2008. pp.229-235, April 2008

[47] Naumov, V.; Baumann, R.; Gross, T., "An evaluation of inter-vehicle Ad-Hoc networks based on realistic vehicular traces", In Proceedings of the 7th ACM international symposium on Mobile Ad-Hoc networking and computing (MobiHoc '06). New York, pp.108-119, 2006

[48] Hao W.; Richard F.; Randall G.; Michael H., "MDDV: a mobility-centric data dissemination algorithm for vehicular networks", In Proceedings of the 1st ACM international workshop on Vehicular Ad-Hoc networks (VANET '04). ACM, New York, NY, USA, pp.47-56, 2004

[49] Mohammadi, A.A.; Raj, G.S.; Karthick, R.V., "ABSTAR: Improves Qos for city environment in VANET," 2013 Fifth International Conference on Advanced Computing (ICoAC), , pp.458-462, Dec. 2013

[50] Jing Z.; Guohong C., "VADD: Vehicle-Assisted Data Delivery in Vehicular Ad-Hoc Networks," INFOCOM 2006. In Proceedings of 25th IEEE International Conference on Computer Communications, pp.1-12, April 2006

[51] Tokuda, K.; Akiyama, M.; Fujii, H., "DOLPHIN for inter-vehicle communications system," In Proceedings of the IEEE Intelligent Vehicles Symposium, 2000. pp.504-509, 2000

[52] Yuanguo B.; Hai Z.; Xuemin S., "A Directional Broadcast Protocol for Emergency Message Exchange in Inter-Vehicle Communications," IEEE International Conference on Communications, 2009. ICC '09., pp.1-5, June 2009

[53] Kihl, M.; Sichitiu, M.L.; Joshi, H., "Design and Evaluation of two Geocast Protocols for Vehicular Ad-hoc Networks", Journal of Internet Engineering, Vol. 2, No. 1, pp.127-135, 2008.

[54] Tonguz, O.K.; Wisitpongphan, N.; Fan Bai, "DV-CAST: A distributed vehicular broadcast protocol for vehicular Ad-Hoc networks," IEEE Wireless Communications, vol.17, no.2, pp.47-57, April 2010

[55] G. Caizzone, P. Giacomazzi, L. Musumeci and G. Verticale, "A power control algorithm with high channel availability for vehicular Ad-Hoc networks," in IEEE International Conference on Communications, ICC 2005, May 2005.

[56] Mondal, A.; Mitra, S., "Dynamic and distributed channel congestion control strategy in VANET," Advances in Computing, Communications and Informatics (ICACCI, 2014 International Conference on, pp.1697-1703, Sept. 2014

[57] Chen, Chen; Li, Yajuan; Pei, Qingqi; Chen, Chen, "Avoiding Information Congestion in VANETs: A Congestion Game Approach," 2014 IEEE International Conference on Computer and Information Technology (CIT), pp.105-110, Sept. 2014

[58] Sathianadhan, N.; Gangadharan, S.S.; Narayanan, G., "A delay-based optimum routing protocol scheme for collision avoidance applications in VANETs," 2014 IEEE 27th Canadian Conference on Electrical and Computer Engineering (CCECE), pp.1-5, May 2014

[59] Le Zhang; Valaee, S., "Safety context-aware congestion control for vehicular broadcast networks," 2014 IEEE 15th International Workshop on Signal Processing Advances in 
Wireless Communications (SPAWC), pp.399-403, June 2014

[60] Bansal, G.; Bin Cheng; Rostami, A.; Sjoberg, K.; Kenney, J.B.; Gruteser, M., "Comparing LIMERIC and DCC approaches for VANET channel congestion control," 2014 IEEE 6th International Symposium on Wireless Vehicular Communications (WiVeC), pp.1-7, Sept. 2014

[61] Bansal, G.; Kenney, J.B., "Achieving weighted-fairnessin message rate-based congestion control for DSRC systems," 2013 IEEE 5th International Symposium on Wireless Vehicular Communications (WiVeC), pp.1-5, June 2013

[62] Bansal, G.; Kenney, J.B.; Rohrs, C.E., "LIMERIC: A Linear Adaptive Message Rate Algorithm for DSRC Congestion Control," IEEE Transactions on Vehicular Technology, vol.62, no.9, pp.4182-4197, Nov. 2013

[63] Nasiriani, N.; Fallah, Y.P.; Krishnan, H., "Stability analysis of congestion control schemes in vehicular ad-hoc networks," 2013 IEEE Consumer Communications and Networking Conference (CCNC), pp.358-363, Jan. 2013

[64] Long Le; Baldessari, R.; Salvador, P.; Festag, A.; Wenhui Zhang, "Performance Evaluation of Beacon Congestion Control Algorithms for VANETs," 2011 IEEE Global Telecommunications Conference (GLOBECOM 2011), pp.1-6, Dec. 2011

[65] Reinders, R.; van Eenennaam, M.; Karagiannis, G.; Heijenk, G., "Contention window analysis for beaconing in VANETs," 2011 7th International Wireless Communications and Mobile Computing Conference (IWCMC),pp.1481-1487, July 2011

[66] M. Torrent-Moreno, D. Jiang, and H. Hartenstein, "Broadcast Reception Rates and Effects of Priority Access in 802.II-Based Vehicular Ad-Hoc Networks," III Froc. ACM VANET 2004, Philadelphia, PA, Oct. 2004.

[67] Mittag, J.; Hartenstein, H., "Is CSMA able to coordinate multiple access in vehicular radio channels effectively?," 2012 12th International Conference on ITS Telecommunications (ITST), pp.801-806, Nov. 2012

[68] Torrent-Moreno, M.; Mittag, J.; Santi, P.; Hartenstein, H., "Vehicle-to-Vehicle Communication: Fair Transmit Power Control for Safety-Critical Information," IEEE Transactions on Vehicular Technology, vol.58, no.7, pp.3684-3703, Sept. 2009

[69] Schmidt R. K.; Brakemeier A.; Leinmuller T.; Kargl F.; Schafer G., "Advanced carrier sensing to resolve local channel congestion," in Proceedings of the Eighth ACM international workshop on Vehicular inter-networking, ACM VANET 2011, pp.11-20, Sept. 2011.

[70] Stanica, R.; Chaput, E.; Beylot, A.-L., "Physical Carrier Sense in Vehicular Ad-Hoc Networks," 2011 IEEE 8th International Conference on Mobile Adhoc and Sensor Systems (MASS), pp.580-589, Oct. 2011

[71] Viriyasitavat, W.; Tonguz, O.K.; Fan Bai, "UV-CAST: an urban vehicular broadcast protocol," IEEE Communications Magazine, vol.49, no.11, pp.116-124, Nov. 2011

[72] Sommer, C.; German, R.; Dressler, F., "Bi-directionally Coupled Network and Road Traffic Simulation for Improved IVC Analysis," IEEE Transactions on Mobile Computing, vol.10, no.1, pp.3-15, Jan. 2011

[73] Estinet 8.1 [Available online]: http://www.estinet.com/news show3.php?sn=22, [Accessed 13-04-2015]

[74] iTETRIS. [Available online]: http://www.ict-itetris.eulin dex.htm/, [Accessed 13-04-2015]

[75] M. Torrent-Moreno; P. Santi; H. Hartenstein, "Distributed Fair Transmit Power Adjustment for Vehicular Ad-Hoc Networks," 2006 3rd Annual IEEE Communications Society on Sensor and Ad-Hoc Communications and Networks, 2006.
SECON '06, pp.479-488, 28-28 Sept. 2006

[76] SeVeCom, "Secure Vehicular Communications: Security Architecture and Mechanisms for V2V/V2I, Delivarable 2.1, 2007-2008.

[77] Vehicle Safety Communications - Applications (VSC-A) Project, Final Report, DOT HS 811 073, January 2009.

[78] J. F. Kurose and W. K. Ross, Computer Networking: A Top-Down Approach, 5 ed ed., USA: Addison Wesley, 2009.

[79] S. Tanenbaum, Computer Networks, Indianapolis, Indiana: Prentice Hall PTR, 2002.

[80] Y. Xu, E. Altman, and R. El-Azouzi, "QoE analysis of media streaming in wireless data networks," in Proceedings of the 11th International IFIP TC 6 Networking Conference, Prague, Czech Republic, May 2012.

[81] T. H. Luan, X. Shen, and F. Bai, "Integrity-oriented content transmission in highway vehicular Ad-Hoc networks," in Proceedings of the 32nd IEEE Conference on Computer Communications (INFOCOM '13), pp. 2562-2570, Turin, Italy, April 2013.

[82] J. Qin, H. Zhu, Y. Zhu, L. Lu, G. Xue, and M. Li, "POST: exploiting dynamic sociality for mobile advertising in vehicular networks," in Proceedings of the IEEE INFOCOM, Toronto, Canada, April 2014.

[83] Vinel, A.; Belyaev, E.; Lamotte, O.; Gabbouj, M.; Koucheryavy, Y.; Egiazarian, K., "Video transmission over IEEE 802.11p: Real-world measurements," 2013 IEEE International Conference on Communications Workshops (ICC), pp.505,509, June 2013.

[84] Belyaev, E.; Vinel, A.; Surak, A.; Gabbouj, M.; Jonsson, M.; Egiazarian, K., "Robust vehicle-to-infrastructure video transmission for road surveillance applications," IEEE Transactions on Vehicular Technology, vol. PP, no.99, pp.1-12, September 2014.

[85] Ota, K.; Mianxiong Dong; Shan Chang; Hongzi Zhu, "MMCD: Cooperative Downloading for Highway VANETs," IEEE Transactions on Emerging Topics in Computing, vol.3, no.1, pp.34-43, March 2015.

[86] Naeimipoor, F.; Boukerche, A., "A Hybrid Video Dissemination Protocol for VANETs," 2014 IEEE International Conference on Communications (ICC), pp.112-117, June 2014.

[87] Xiaoxiao Jiang; Xiang Cao; Du, D.H.C., "Multihop transmission and retransmission measurement of real-time video streaming over DSRC devices," 2014 IEEE 15th International Symposium on A World of Wireless, Mobile and Multimedia Networks (WoWMoM), pp.1-9, June 2014.

[88] Honghai Wu; Huadong Ma, "Opportunistic routing for live video streaming in vehicular Ad-Hoc networks," 2014 IEEE 15th International Symposium on A World of Wireless, Mobile and Multimedia Networks (WoWMoM), pp.1-3, June 2014.

[89] Changqiao Xu; Futao Zhao; Jianfeng Guan; Hongke Zhang; Muntean, G.-M., "QoE-Driven User-Centric VoD Services in Urban Multihomed P2P-Based Vehicular Networks," IEEE Transactions on Vehicular Technology, vol.62, no.5, pp.2273-2289, Jun 2013.

[90] Quadros, C.; Cerqueira, E.; Santos, A.; Gerla, M., "A Multi-flow-Driven Mechanism to Support Live Video Streaming on VANETs," 2014 Brazilian Symposium on Computer Networks and Distributed Systems (SBRC), pp.468-476, May 2014

[91] B. Bellalta, E. Belyaev, M. Jonsson, and A. Vinel, "Performance evaluation of IEEE 802.11p-enabled vehicular video surveillance system," IEEE Communications Letters, vol. 18, no. 4, pp. 708-711, 2014.

[92] M. Asefi, J. W. Mark, and X. Shen, "A mobility-aware and 
quality-driven retransmission limit adaptation scheme for video streaming over VANETs," IEEE Transactions on Wireless Communications, vol. 11, no. 5, pp. 1817-1827, 2012.

[93] E. Belyaev, A. Cinel, M. Jonsson, and K. Sjoberg, "Live video streaming in IEEE $802.11 \mathrm{p}$ vehicular networks: demonstration of an automotive surveillance application," in Proceedings of the IEEE Conference on Computer Communications Workshops (INFOCOM WKSHPS '14), pp. 131-132, Toronto, Canada, April-May 2014.

[94] A. Bradai and T. Ahmed, "ReViV: selective rebroadcast mechanism for video streaming over VANET," in Proceedings of the IEEE 79th Vehicular Technology Conference (IEEE VTC '14), Seoul, Korea, May 2014.

[95] C. Rezende, A. Mammeri, A. Boukerche, and A. A. F. Loureiro, "A receiver-based video dissemination solution for vehicular networks with content transmissions decoupled from relay node selection," Ad-Hoc Networks, vol. 17, pp. 1-17, 2014.

[96] Yun Chen; Xuelian Cai; Mingyu Gao; Xin Wang; Lina Zhu; Changle Li, "Dynamic Overlay-Based Scheme for Video Delivery over VANETs," in 2014 IEEE 80th Vehicular Technology Conference (VTC Fall), pp.1-5, 14-17 Sept. 2014

[97] IEEE Standard for Wireless Access in Vehicular Environments (WAVE) -- Multi-channel Operation Corrigendum 1: Miscellaneous Corrections," IEEE Std 1609.4-2010/Cor 1-2014 (Corrigendum to IEEE Std 1609.4-2010), pp.1-30, December 23 2014.

[98] Yu, X.; Navaratnam, P.; Moessner, K.; Cruickshank, H., "Distributed Resource Reservation in Hybrid MAC with Admission Control for Wireless Mesh Networks," IEEE Transactions on Vehicular Technology, vol.PP, no.99, pp.1-13, January 2015.

[99] Mak, T.K.; Laberteaux, K.P.; Sengupta, Raja; Ergen, M., "Multichannel Medium Access Control for Dedicated Short-Range Communications," IEEE Transactions on Vehicular Technology, vol.58, no.1, pp.349-366, January 2009.

[100] So, J., Vaidya, N.: Multi-channel MAC for Ad-Hoc networks: handling multi-channel hidden terminals using a single transceiver. In: ACM International Symposium on Mobile Ad-Hoc Networking and Computing (MOBIHOC), pp. 222-233, 2004.

[101] Strom, E.G: On Medium Access and Physical Layer Standards for Cooperative Intelligent Transport Systems in Europe. Proceedings of IEEE, 99(7), Pp1183-1188 (2011).

[102] Campolo, C.; Koucheryavy, Y.; Molinaro, A.; Vinel, A., "Characterizing broadcast packet losses in IEEE 802.11p/WAVE vehicular networks," 2011 IEEE 22nd International Symposium on Personal Indoor and Mobile Radio Communications (PIMRC), pp.735-739, 11-14 September 2011.

[103] Xiaoyan Yin; Xiaomin Ma; Trivedi, K.S.; Vinel, A., "Performance and Reliability Evaluation of BSM Broadcasting in DSRC with Multi-Channel Schemes," IEEE Transactions on Computers, vol.63, no.12, pp.3101-3113, December 2014.

[104] Jagadeesh Kakarla and Siva sathya; "A Survey and Qualitative Analysis of Multi-channel MAC Protocols for VANET," International Journal of Computer Applications, Vol. 38, No.6, Pp 38-42, January 2012.

[105] Campolo, Claudia; Molinaro, Antonella, "Improving multi-channel operations in VANETs by leveraging stopped vehicles," 2013 IEEE 24th International Symposium on Personal Indoor and Mobile Radio Communications (PIMRC), pp.2229-2233, 8-11 Sept. 2013.

[106] Morgan, Y.L., "Notes on DSRC \& WAVE Standards Suite: Its Architecture, Design, and Characteristics," IEEE
Communications Surveys \& Tutorials, vol.12, no.4, pp.504-518, Fourth Quarter 2010.

[107] Uzcategui, R.; Acosta-Marum, G., "Wave: A tutorial," IEEE Communications Magazine, vol.47, no.5, pp.126-133, May 2009. [108] Hang Su; Xi Zhang, "Clustering-Based Multichannel MAC Protocols for QoS Provisionings Over Vehicular Ad-Hoc Networks," in IEEE Transactions on Vehicular Technology, vol.56, no.6, pp.3309-3323, Nov. 2007.

[109] Minming Ni; Zhangdui Zhong; Dongmei Zhao, "A novel multichannel multiple access protocol for vehicular Ad-Hoc networks," 2012 IEEE International Conference on Communications (ICC), pp.528-532, June 2012.

[110] Yunpeng Zang, Lothar Stibor, Bernhard Walke, Hans-Jürgen Reumerman and Andre Barroso, "A Novel MAC Protocol for Throughput Sensitive Applications in Vehicular Environments", Vehicular Technology Conference, IEEE 2007.

[111] IEEE Approved Draft Standard for Wireless Access in Vehicular Environments (WAVE)--Multi-channel Operation Corrigendum 1: Correct identified errors," IEEE P1609.4-2010/Cor1/D4, August 2014, pp.1-24, Dec. 142014.

[112] T. K. Mak; K. P. Laberteaux; Sengupta, Raja; M. Ergen, "Multichannel Medium Access Control for Dedicated Short-Range Communications," IEEE Transactions on Vehicular Technology, , vol.58, no.1, pp.349-366, Jan. 2009.

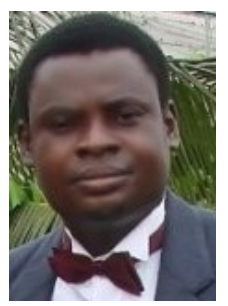

Elias Chinedum Eze obtained his B.Sc. (Hons) degree in Computer Science at the Ebonyi State University Abakaliki, Nigeria in 2006. He completed his M.Sc. degree in computer networking from University of Bedfordshire, UK in 2012, and is currently a PhD candidate at University of Bedfordshire, UK. He has been a lecturer at the Department of Computer Science, Ebonyi State University Abakaliki, Nigeria since November 2012. His research interests include data dissemination in vehicular Ad-Hoc networks and mobile Ad-Hoc networks, intelligent transportation system, vehicular Ad-Hoc networks, mobile computing, wireless computing, context-aware systems, computer and mobile security. E-mail: elias.eze@study.beds.ac.uk (Corresponding author). ORCID iD: 0000-0003-1121-2837

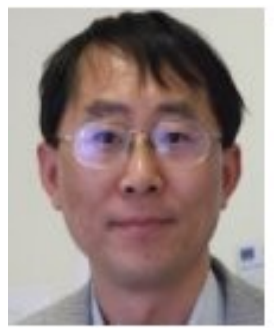

Sijing Zhang obtained his B.Sc. and M.Sc. degrees, both in computer science, from Jilin University, Changchun, China in 1982 and 1988, respectively. $\mathrm{He}$ earned a $\mathrm{PhD}$ degree in computer science from the University of York, UK in 1996. He then joined the Network Technology Research Centre (NTRC) of Nanyang Technological University, Singapore as a post-doctoral fellow. In 1998, he returned to the UK to work as a research fellow with the Centre for Communications Systems Research (CCSR) of the University of Cambridge. $\mathrm{He}$ joined the School of Computing and Technology, University of Derby, UK, as a senior lecturer in 2000. Since October 2004, he has been working as a senior lecturer in the Department of Computer Science and Technology, University of Bedfordshire, UK. His research interests include real-time scheduling algorithms, 
schedulability tests for hard real-time traffic, performance analysis and evaluation of real-time communication protocols, and wireless networks for real-time industrial applications.

E-mail: Sijing.Zhang@beds.ac.uk

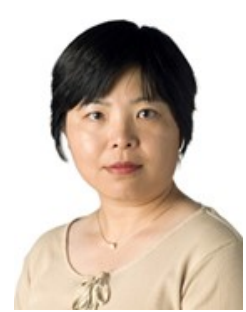

Enjie Liu obtained her BSc in Computer Science at Northwest University, China in June 1987.She worked on voice/data networking for several years in Nortel Post \& Telecommunication Technical Inc. (NPT), a joint-venture company of Nortel Networks and Xian Institute of Post and Telecommunications in China. She got her PhD degree from Queen Mary College, University of London, in March 2002. Her research topic was hybrid queuing model for fast network performance analysis. She then worked as a research fellow on an EU IST (European Union Information Society Technologies) project in the Centre for Communication Systems Research (CCSR) at the University of Surrey. Dr Liu joined the University of Bedfordshire in September 2003. Her research interests include Big-data management and mining, Applications for Internet of Things (IoT), Mobility management with Femtocells, Handset energy efficiency in mobile networks, Wireless networking, Data Communications, Managing Networks, and e-Commerce Technology.

E-mail: Enjie.Liu@beds.ac.uk

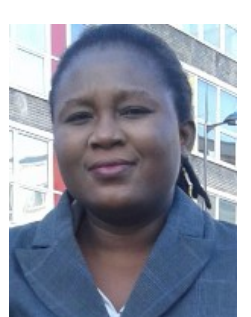

Joy Chinedu Eze obtained her B.Sc. (Hons) degree in Industrial Mathematics/Computer Science at the Ebonyi State University Abakaliki, Nigeria in 2007. She completed her M.Sc. degree in Mathematical Optimization from Ebonyi State University Abakaliki, Nigeria in 2014, and is currently a $\mathrm{PhD}$ candidate at University of Bedfordshire, UK. She has been an academia at the Department of Industrial Mathematics and Applied Statistics/Computer Science, Ebonyi State University Abakaliki, Nigeria since February 2010. Her research interests include mathematical optimization, linear programming (LP), Lagrange duality, application of optimization methods for radio resource management in communication networks, intelligent transportation system, vehicular Ad-Hoc networks, mobile computing, and wireless computing.

E-mail: joy.eze1@study.beds.ac.uk 